This PDF is a selection from a published volume from the National Bureau of Economic Research

Volume Title: Fiscal Policy and Management in East Asia, NBER-EASE, Volume 16

Volume Author/Editor: Takatoshi Ito and Andrew K. Rose, editors

Volume Publisher: University of Chicago Press

Volume ISBN: 978-0-226-38681-2

Volume URL: http://www.nber.org/books/ito_07-1

Conference Date: June 23-25, 2005

Publication Date: October 2007

Title: Measuring the Effectiveness of Fiscal Policy in Korea Author: Seok-Kyun Hur

URL: http://www.nber.org/chapters/c0371 


\title{
Measuring the Effectiveness \\ of Fiscal Policy in Korea
}

\author{
Seok-Kyun Hur
}

\subsection{Introduction}

The purpose of this paper is to empirically test whether fiscal adjustments can contribute to smoothing economic fluctuations. It is well known that there have been two competing views on this issue, one of whichknown as Keynesian - emphasizes the effectiveness of fiscal policy, and the other of which - the so-called new classical school-refutes it on the grounds of the crowding-out effect and Ricardian equivalence. Considering that these two conflicting arguments stem from the emphasis on the different perceptions of reality (such as the bounded rationality and finite lives of economic agents), it would be more appropriate to do an empirical analysis rather than continue theoretical debates.

This research mainly concerns a trajectory of GDP induced by variations in fiscal expenditure and taxation policy. ${ }^{1}$ We estimate three variable vector autoregression (VAR) models or structural VAR models with Korean fiscal data in order to measure the magnitudes of fiscal multipliers dynamically following changes in fiscal expenditure and taxation. However, the quarterly Korean fiscal and GDP data (covering from 1979 Q1 to

Seok-Kyun Hur is a fellow at the Korea Development Institute.

The author acknowledges valuable comments from Wei Li, Fred Yum, Youngsun Koh, and other participants at the 16th NBER-EASE in Manila. He is also grateful to Hyun-Ah Kim for research assistance. All remaining errors are his own.

1. In discussing the validity of fiscal policy in reigning business cycles, the importance of timeliness matters as much as the directions of policy effects due to the presence of policy time lags. To rephrase, the effectiveness of fiscal policy would not be achieved unless it is well synchronized with the changes in the economic environments. However, it would constitute another paper beyond the scope of this one to evaluate the stabilizing function of fiscal policy. 
2000 Q4) reveal that expansive fiscal policy has no significant or substantial effect on boosting the economy.

In order to check the robustness of our results, we assign different combinations of identifying restrictions on the disturbances of the tested SVAR systems and measure the corresponding fiscal multipliers. Shock identification strategies are elected based on the institutional aspect of fiscal activities (i.e., how the government reacts to business cycles by means of controlling the size of tax revenues and expenditures). Observing how the estimated values of fiscal multipliers vary with respect to the restrictions, we find that the estimated fiscal multipliers of Korea decay very fast in addition to their small size and low statistical significance.

Then, considering the dependency of Korean economy on the foreign sector, we extend the three variable SVARs to four variable ones by adding a variable reflecting external shocks. Results from the four variable SVARs confirm those from the three variable models while the significance of the effectiveness of fiscal policy is generally enhanced.

The contents of the paper are organized as follows. Section 3.2 surveys the relevant literature (from both Korean and foreign sources) on the issue. Section 3.3 introduces an analytical tool of the paper, basically a SVAR system. Started from the usual Cholesky decomposition, we extend the setup to include other strategies of identification borrowed from Blanchard and Perotti (2002) and Koh (2002). Section 3.4 provides empirical results from applying the methodologies defined in section 3.3 to the case of Korea. Finally, section 3.5 concludes.

\subsection{Literature}

Currently available literature on the effectiveness of fiscal policy is easily classified into two groups by methodologies. The first group of papers calibrates a general equilibrium model and provides either comparative statics or a transitional path in response to variations in fiscal stance of the government. The use of the general equilibrium setup is desirable for its internal consistency. However, it cannot provide an exact closed-form solution. Thus, inevitably it resorts to diverse numerical techniques to get a solution.

On the other hand, the second group of papers estimate a reduced equation or a system of reduced equations liking fiscal variables with GDP or a component of income identity (for example, aggregate consumption). ${ }^{2}$ In return for its relatively easy application, such econometric approaches are criticized for the absence of economics. Hence, their proper implementation should be based on theoretical reasoning.

Our paper positions itself in the second category. This is because the re-

2. Some literature focuses on price variables (such as interest, GDP deflator, and exchange rates) rather than these quantity variables. 
sults from a general equilibrium setup are likely to be predetermined by the parametric assumptions. In other words, the parametric structure of the setup may exaggerate the relation between any pair of target variables in a certain direction, which is either presumed or unknown for most cases. In contrast, the econometric approach is relatively free from such an issue of predetermination. Of course, the econometric approach is not perfectly exempt from the contamination of biases. For example, a single-equation approach (Feldstein 1982, Kormendi 1983, and Lee and Sung 2005) should come up with a proper strategy for eliminating the potential biases. Accordingly, our paper adopts a structural VAR setup, which is known to avoid the endogeneity or simultaneity among the variables involved.

In this section, rather than display all the spectrum of the relevant literature aforementioned, we narrow down the scope to cover ones using a VAR setup. ${ }^{3}$

\subsubsection{Korean Literature}

Several selections from the Korean literature, all of which disseminate Korean fiscal and macro data with a VAR setup to evaluate the effectiveness of fiscal policy on the aggregate economy, are summarized in table 3.1. Clearly, we can see that their results diverge in regard to the effectiveness of fiscal policy depending on the data sets and the choice of key variables.

Another notable point is that most of Korean literature using a VAR setup rely only on the Cholesky decomposition for a shock-identifying strategy. Admittedly, Cholesky decomposition is one of the most basic shockidentification schemes in VAR, and so it cannot represent all the possible contemporaneous relations among the disturbances. In this context, we need to search for other shock-identifying strategies from the foreign literature on this issue and apply them to the available Korean fiscal data.

\subsubsection{Foreign Literature}

Most of the research on the effectiveness of fiscal policy adopts a structural VAR setup. According to De Castro and Hernandez de Cos (2006), the literature using SVAR are categorized into four groups, as shown in table 3.2, by differences in the fiscal shock-identifying strategies. ${ }^{4}$

Such popularity of SVAR lies in the fact that it is less dependent on the existing economic theory and is less susceptible to the symptoms of endogeneity and cointegration among the variables of our interest. ${ }^{5}$ However,

3. For the literature of other approaches, see Hemming, Kell, and Mahfouz (2002).

4. Perotti (2004) classifies the SVAR literature into three groups. De Castro and Hernandez de Cos (2006) add an additional group of the literature, which includes Blanchard and Perotti (2002) and Perotti (2004).

5. Even when cointegrated relations exist among the key variables, the use of plain vanilla VAR can still be advocated on the grounds that the parameters are estimated consistently and the estimates have the same asymptotic distribution as those of differenced data (Hamilton 1994). 


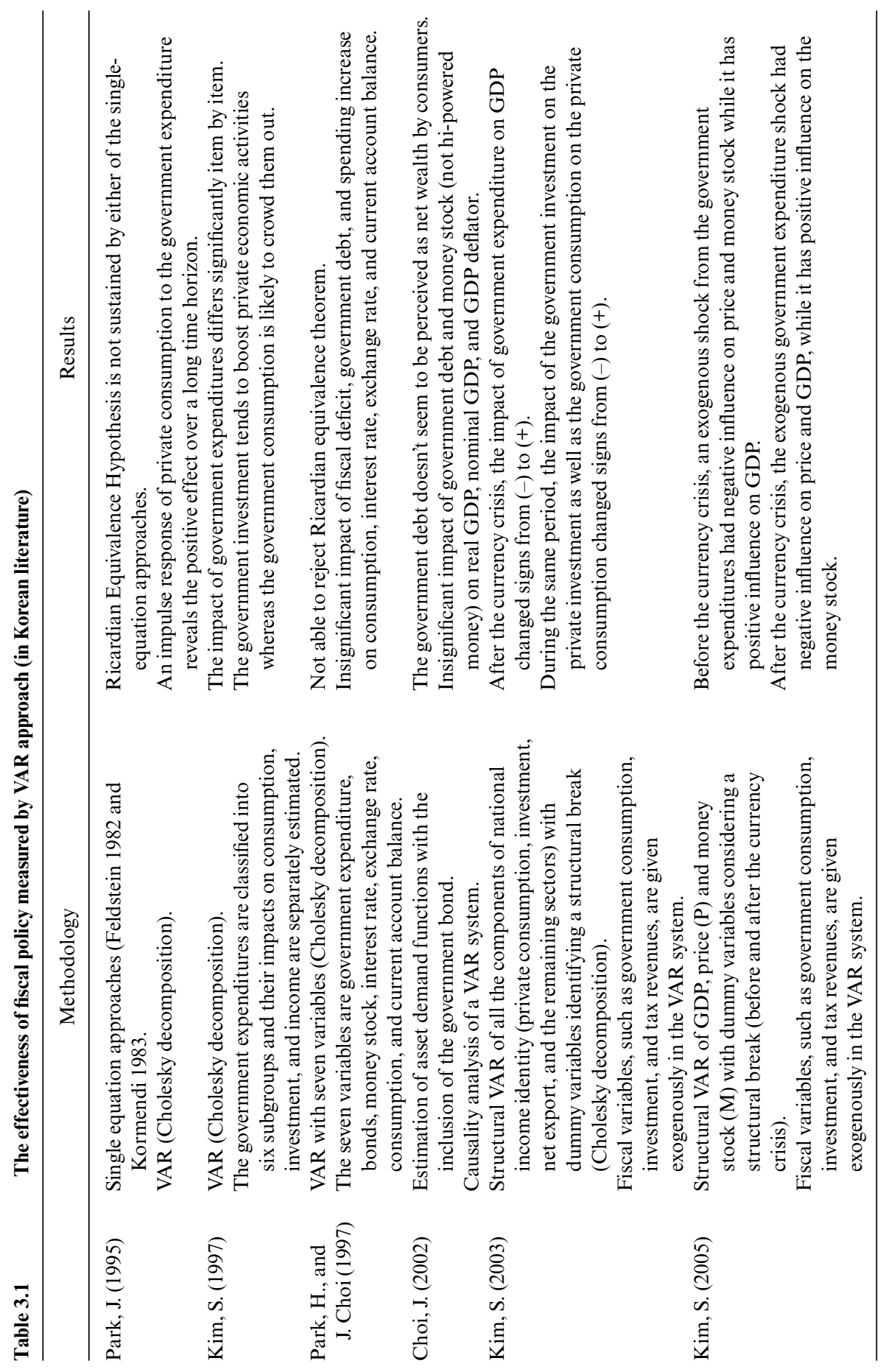


Various shock identification strategies adopted in measuring the effectiveness of fiscal policy

\begin{tabular}{lc}
\hline & \multicolumn{1}{c}{ Shock identification strategy } \\
\hline $\begin{array}{l}\text { Ramey and Shapiro (1998) and Edelberg, } \\
\text { Eichenbaum, and Fisher (1999) }\end{array}$ & $\begin{array}{c}\text { VAR models with dummy variables specifying } \\
\text { certain episodes (such as wars and drastic } \\
\text { changes in fiscal stance). }\end{array}$ \\
$\begin{array}{c}\text { VAR with sign restrictions on the impulse } \\
\text { response functions. }\end{array}$ \\
$\begin{array}{c}\text { Fatas and Mihov (2000), Favero (2002), } \\
\text { and De Castro (2004) }\end{array}$ \\
$\begin{array}{c}\text { Slanchard and Perotti (2002), Perotti } \\
\text { (1999), and Hoppner (2002) }\end{array}$ & $\begin{array}{c}\text { SVAR using institutional information and } \\
\text { quarter dependence. }\end{array}$ \\
\hline
\end{tabular}

${ }^{a}$ Hoppner (2002), following the shock representation by Blanchard and Perotti (2002), concentrates on distinguishing the direct effect of fiscal shock from the indirect effect of the Automatic Stabilization Mechanism (ASM).

the use of SVAR is more challenging in analyzing the fiscal policy than in analyzing the monetary policy for several reasons, such as the existence of uncertain or unidentifiable policy lags and the automatic stabilization mechanism. These factors, combined with the low frequency of fiscal data (mostly quarterly), cause technical difficulties in identifying sources of correlations or causalities among the disturbances of the VAR system and disentangling the contributions of the built-in stabilization mechanism. Thus, the recent development in analyzing the fiscal policy using the VAR setup naturally has been concentrated on handling those problems.

\subsection{Methodology}

Our model adopts a SVAR system based on Blanchard and Perotti (2002) and De Castro (2004). Accordingly, it emphasizes the design of a shock-identification scheme so that it can allow more realistic contemporaneous relations among key variables in the SVAR equations.

Here we choose three key variables - real GDP $\left(Y_{t}\right)$, government expenditure $\left(G_{t}\right)$, and tax revenue $\left(T_{t}\right)$. All of them are logarized after being divided by population size. A vector consisting of these three variables, $X_{t}$, is assumed to follow a VAR system:

$$
X_{t}=A(L) X_{t-1}+D_{t}+U_{t}, X_{t} \equiv\left(\begin{array}{c}
T_{t} \\
G_{t} \\
Y_{t}
\end{array}\right), U_{t} \equiv\left(\begin{array}{c}
t_{t} \\
g_{t} \\
y_{t}
\end{array}\right)
$$

In the previous equation, each element of the vector $D_{t}$ represents the long-term trend of the corresponding variable, which is, in turn, assumed 
to have no influence on the long-term trends of the other variables. Such long-run independence among the variables indicates our implicit assumption that there is no long-run effect of fiscal measures on GDP. Thus, our model is focused on evaluating the effectiveness of fiscal policy not in terms of raising the long-run economic growth but in terms of controlling the short-term fluctuations.

Before discussing further the detrending procedure, we have to consider that all the components in $X_{t}$ tend to have seasonality. Blanchard and Perotti (2002) introduce quarterly dependency to the estimation of $A(L)$ in a form of $A(L, q)$ instead of using seasonally adjusted data. Depending on the number of observations available, the use of the quarterly dependent version of equation (1) could be considered. Otherwise, a usual method of eliminating the seasonality, such as X-12, could be applied.

So far the VAR system in equation (1) has not been fully specified. Detailed assumptions on the disturbance term $U_{t}$ as well as the long-term trend $D_{t}$ are added as follows. To begin with, two types of detrending procedures are taken in the paper. One is linearly detrending with respect to time $\left(X^{L D}\right)$ and the other is detrending by Hodrick-Prescott filtered data $\left(X^{D H P}\right)$.

$$
X_{t}^{L D} \equiv X_{t}-D t, X_{t}^{D H P} \equiv X_{t}-X_{t}^{H P}
$$

By plugging $X^{L D}$ or $X^{D H P}$, we represent the VAR system of equation (1) in a neat way.

$$
\begin{aligned}
X_{t}^{D H P} & =A(L) X_{t-1}^{D H P}+U_{t} \\
X_{t}^{L D} & =A(L) X_{t-1}^{L D}+U_{t}
\end{aligned}
$$

The long-term time trend $D_{t}$ disappears in equation (2) because the vectors $X^{L D}$ and $X^{D H P}$ are consisting of detrended variables.

Second, our paper tries three different specifications on the disturbance term $U_{t}$. A general form of $U_{t}$ could be represented as follows ( $\left[e_{t}^{t}, e_{t}^{g}, e_{t}^{y}\right]$ are orthogonal to each other):

$$
\left(\begin{array}{c}
t_{t} \\
g_{t} \\
y_{t}
\end{array}\right) \equiv\left(\begin{array}{ccc}
0 & \alpha_{2} & \alpha_{3} \\
\beta_{1} & 0 & \beta_{3} \\
\gamma_{1} & \gamma_{2} & 0
\end{array}\right)\left(\begin{array}{c}
t_{t} \\
g_{t} \\
y_{t}
\end{array}\right)+\left(\begin{array}{ccc}
1 & a_{2} & a_{3} \\
b_{1} & 1 & b_{3} \\
c_{1} & c_{2} & 1
\end{array}\right)\left(\begin{array}{c}
e_{t}^{t} \\
e_{t}^{g} \\
e_{t}^{y}
\end{array}\right)
$$

Due to identifiability, equation (3) requires additional restrictions on the coefficients. As special cases of the previous equation, we consider Cholesky decomposition (in various combinations of ordering variables) and two identification strategies exploiting institutional information.

First, the Cholesky decomposition restricts the coefficients of equation (3) in the following way (for example, in the order of tax revenue, expenditure, and GDP): 


$$
\left(\begin{array}{l}
t_{t} \\
g_{t} \\
y_{t}
\end{array}\right) \equiv\left(\begin{array}{lll}
0 & 0 & 0 \\
0 & 0 & 0 \\
0 & 0 & 0
\end{array}\right)\left(\begin{array}{l}
t_{t} \\
g_{t} \\
y_{t}
\end{array}\right)+\left(\begin{array}{ccc}
1 & 0 & 0 \\
b_{1} & 1 & 0 \\
c_{1} & c_{2} & 1
\end{array}\right)\left(\begin{array}{c}
e_{t}^{t} \\
e_{t}^{g} \\
e_{t}^{y}
\end{array}\right)
$$

Identification of shocks by Cholesky decomposition, though easy to use, is vulnerable to change in the order of decomposition, which is usually arbitrarily set. ${ }^{6}$ Therefore, in the case of using the Cholesky decomposition without any prior information about the structure of shocks, all the probable combinations of shock orderings should be tested and compared for robustness check. ${ }^{7}$

Another problematic feature of Cholesky decomposition lies in that it defines the contemporaneous relation among the disturbance term $U_{t}$ only in a recursive way. Accordingly, nonrecursively structured contemporaneous relations could not be identified by the Cholesky decomposition. Furthermore, the misspecification of the contemporaneous relation results in an imprecise estimation of impulse responses both in terms of sign and magnitude.

Second, as a typical example of institutional identification strategies, we adopt Blanchard and Perotti (B-P; 2002), whose shock identification is represented as

$$
\left(\begin{array}{c}
t_{t} \\
g_{t} \\
y_{t}
\end{array}\right) \equiv\left(\begin{array}{ccc}
0 & 0 & \alpha_{3} \\
0 & 0 & \beta^{3} \\
\gamma_{1} & \gamma_{2} & 0
\end{array}\right)\left(\begin{array}{l}
t_{t} \\
g_{t} \\
y_{t}
\end{array}\right)+\left(\begin{array}{ccc}
1 & a_{2} & 0 \\
b_{1} & 1 & 0 \\
0 & 0 & 1
\end{array}\right)\left(\begin{array}{c}
e_{t}^{t} \\
e_{t}^{g} \\
e_{t}^{y}
\end{array}\right)
$$

Equation (5) reduces the number of parameters to estimate by borrowing the information on the GDP (or tax base) elasticities of tax revenue $\left(\alpha_{3}\right)$ from external sources. In addition, B-P assume the GDP shock has no contemporaneous impact on the government spending $\left(\beta_{3}=0\right)$. Then, they divide equation (5) into two cases by setting $a_{2}=0$, or $b_{1}=0$, alternatively.

The third identification strategy, which also depends on the institutional information, borrows the restrictions on $\beta_{1}$ and $\beta_{3}(=0)$ from the budget data in addition to $\alpha_{3}$, based on the almost common perception that the government of Korea has kept the principle of "Expenditure within Revenue" since the 1980s (Koh 2002 and Lee and Kim 2004). ${ }^{8}$ Due to the long

6. In most cases shock ordering is determined by the Granger causality test. However, the test itself is very vulnerable to permitted number of lags. Furthermore, it cannot put shocks in order when the causality holds in both directions between any pair of the variables.

7. De Castro (2004) analyzes a five-variable VAR model with varying orders of Cholesky decomposition. The five variables include price and interest rate in addition to GDP, government spending, and tax revenue. Due to the inclusion of the price variables, the five-variable setup could examine the crowding-out effect revealed on them.

8. Quoted from Koh (2002): "One important principle in fiscal management was established in this period. It was the principle of 'Expenditure within Revenue,' or the balanced 
tradition of balanced budget, the level of expenditure still tends to be determined within the revenue forecasts. Exploiting such fiscal conservatism, we assign a restriction on $\beta_{1}$ by running a regression of expenditure increment on tax revenue increase and borrowing the coefficient thereof. Compared with previous identification strategies, the third one highlights the contemporaneous relation in the disturbance term $U_{t}$.

$$
\left(\begin{array}{c}
t_{t} \\
g_{t} \\
y_{t}
\end{array}\right) \equiv\left(\begin{array}{lll}
0 & \alpha_{2} & \alpha_{3} \\
\beta_{1} & 0 & \beta_{3} \\
\gamma_{1} & \gamma_{2} & 0
\end{array}\right)\left(\begin{array}{c}
t_{t} \\
g_{t} \\
y_{t}
\end{array}\right)+\left(\begin{array}{lll}
1 & 0 & 0 \\
0 & 1 & 0 \\
0 & 0 & 1
\end{array}\right)\left(\begin{array}{c}
e_{t}^{t} \\
e_{t}^{g} \\
e_{t}^{y}
\end{array}\right)
$$

In the next section we report the results from applying equations (4) through (6) to equation (2) sequentially. Impulse-response functions are estimated with their 95 percent confidence intervals. ${ }^{9}$ By comparing the results derived from different contemporaneous relations among the shocks, we could check the robustness of the SVAR models.

\subsection{Empirical Results}

\subsubsection{Data}

Our empirical works are based on the data in Monthly Statistical Bulletin, published by Bank of Korea. The data set includes the period from 1979Q1 to 2000Q4. However, its time coverage cannot be extended beyond year 2000 because, as of 2001, the Korean government introduced a new fiscal information system based on the consolidated budget, which is not compatible with the old data. Furthermore, the new data set of consolidated budget is not back-dated prior to 1994. Though the concept of consolidated budget seems more appropriate for the purpose of our research, we choose the Bank of Korea data for their relatively long span of time series.

Figure 3.1 draws the past trends of the government expenditure, tax revenue, and GDP, all of which are measured in logarized per capita real terms. It shows all the three variables tend to follow certain time trends. In addition, though not apparent in the figure, we observe that strong seasonality is present in all of the three variables. Thus, we process the data by eliminating seasonality (X-12) and the long-term time trend (linear time trend or H-P filtered) sequentially.

In order to check the presence of nonstationarity, Augmented Dickey Fuller (ADF) unit root tests are done for the variables, which are already seasonally adjusted and detrended $\left(X^{L D}, X^{D H P}\right)$. The tests report that only

budget principle. While not formalized in a law or a regulation, it acted as self-discipline imposed on the budget authorities against imprudent management of the budget."

9. The confidence level of 95 percent is used because it is a sort of academic norm. However, when the results are reflected on policy making, the level of 95 percent may not be taken as a golden rule. 


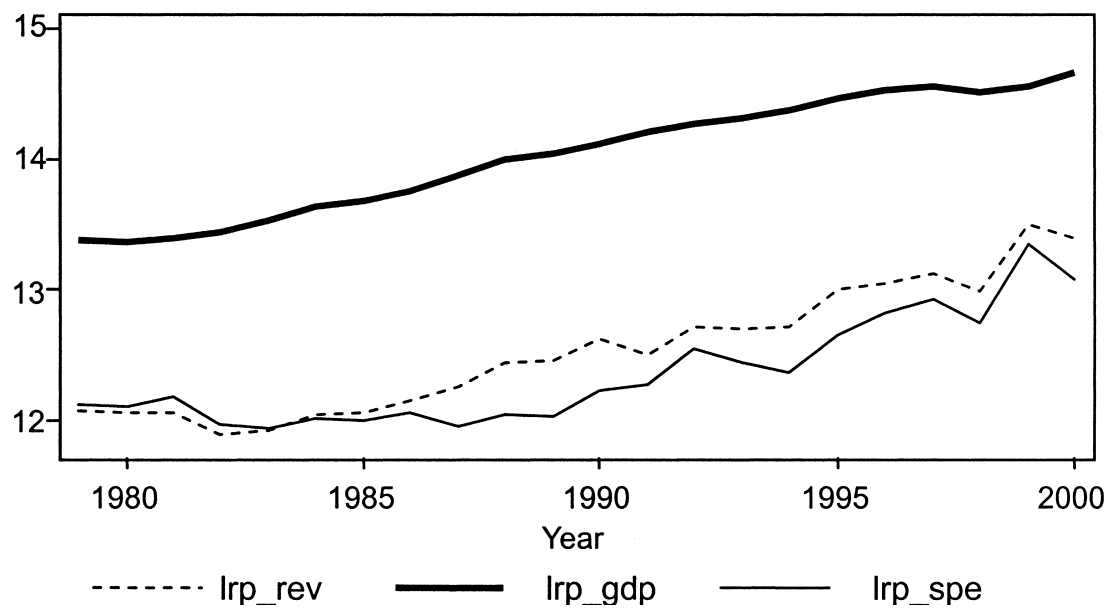

Fig. 3.1 Trends of government expenditure, tax revenue, and GDP (quarterly data from 1979Q1-2000Q4)

the linearly detrended $Y_{t}$ (the logarized per capita real GDP) seems to follow $I(1) .^{10}$

\subsubsection{Results}

Tested models have in common that all the variables used are logarized and their differences denote change rates of the corresponding variables. Accordingly, the values of impulse responses denote the GDP growth rates over a certain period following an innovation (of a certain magnitude) in the growth rate of tax revenue, or expenditure, or GDP itself.

In addition, the size of innovation to be applied in calculating an impulse response function is set to be 1 standard deviation of each error term in $\left(e_{t}^{t}, e_{t}^{g}, e_{t}^{y}\right)$. Hence, the elasticity of per capita GDP with respect to either of the fiscal stimuli is defined to be the ratio of log GDP change (GDP growth rate) to the sample standard deviation of the corresponding innovation term (the change rate of the relevant fiscal variable).

Considering that the current government expenditure and tax revenue in Korea is roughly 25 to 30 percent of GDP in size, we can convert the elasticity of per capita GDP to fiscal stimulus into a usual fiscal multiplier by multiplying 3 or 4 to the elasticity.

Lag orders used in the VAR estimations are set to four, as is selected by Akaike's Information Criteria (AIC). The lag order of 4 is quite common in other literature using quarterly data, such as Blanchard and Perotti (2002) and De Castro (2004).

10. Rothenberg and Stock (1997) show that the coefficients of a VAR system estimated by OLS are consistent even though some level variables follow I(1). 
Table 3.3 Impulse-response functions of key variables (linearly detrended) by Cholesky ordering (in the order of tax revenue, expenditures, GDP)

\begin{tabular}{lrrrrrr}
\hline Quarter & OIRF(1) & Lower(1) & Upper(1) & OIRF(2) & Lower(2) & Upper(2) \\
\hline 0 & 0.0034 & -0.0001 & 0.0068 & 0.0042 & 0.0009 & 0.0076 \\
1 & 0.0011 & -0.0037 & 0.0058 & 0.0054 & 0.0008 & 0.0101 \\
2 & -0.0013 & -0.0073 & 0.0047 & 0.0067 & 0.0011 & 0.0123 \\
3 & -0.0033 & -0.0102 & 0.0037 & 0.0075 & 0.0010 & 0.0141 \\
4 & -0.0049 & -0.0121 & 0.0023 & 0.0042 & -0.0027 & 0.0112 \\
5 & -0.0064 & -0.0139 & 0.0010 & 0.0038 & -0.0036 & 0.0113 \\
6 & -0.0084 & -0.0160 & -0.0008 & 0.0031 & -0.0046 & 0.0108 \\
7 & -0.0089 & -0.0167 & -0.0011 & 0.0021 & -0.0059 & 0.0100 \\
8 & -0.0087 & -0.0166 & -0.0008 & 0.0016 & -0.0065 & 0.0096 \\
9 & -0.0088 & -0.0168 & -0.0008 & 0.0011 & -0.0071 & 0.0093 \\
10 & -0.0088 & -0.0169 & -0.0008 & 0.0003 & -0.0080 & 0.0087 \\
\hline
\end{tabular}

Notes: 95 percent lower and upper bounds reported. (1) impulse $=$ tax revenue, and response $=$ GDP. $(2)$ impulse $=$ expenditures, and response $=$ GDP.

\section{Cholesky Decomposition}

Table 3.3 summarizes the estimation results of equation (4) in the order of tax revenue, government expenditure, and real GDP with the linearly detrended data. Dividing the responses of GDP to the impulses of tax revenue and the government spending in table 3.3 by the estimated sample standard deviations of innovation terms $\left(e_{t}^{t}, e_{t}^{g}, e_{t}^{y}\right)=(0.085,0.058,0.016)$, we can obtain the elasticities of GDP with respect to fiscal stimuli, which can be in turn converted into series of fiscal multipliers. Figure 3.2 draws impulse-response functions for all the three variables.

According to table 3.3, impulse responses of GDP have significantly negative values for the sixth to tenth quarters after a shock in tax revenue. On the other hand, impulse responses to an expenditure shock hold significantly negative signs up to the third quarter. By dividing them first by $\left(e_{t}^{t}\right.$, $\left.e_{t}^{g}\right)=(0.085,0.058)$ each and multiply them by 3 to 4 next, we can convert these significant estimates of impulse responses to fiscal multipliers. ${ }^{11}$ The accumulated fiscal multipliers of tax revenue and government spending (up to 10 quarters) are about $-2 \sim-1.5$ and $1.2 \sim 1.6 .{ }^{12}$ Though these numbers seem plausible in terms of signs and magnitudes, they are based on the estimates for $c_{1}$ and $c_{2}$, which interpret the contemporaneous relations between $t_{t}, g_{t}$ and $y_{t}$ imprecisely. ${ }^{13}$ Therefore, the results in table 3.3 should not be heavily relied on.

11. An accumulated fiscal multiplier is the sum of fiscal multipliers up to the current period.

12. Here an accumulated fiscal multiplier is defined to be the sum of impulse responses, which reject a null hypothesis of zero value with 5 percent significance.

13. Especially the estimate for $c_{1}$ holds a positive sign, which implies that tax revenue increase has positive contemporaneous impact on GDP. However, it would be more appropriate to assume that GDP increase has positive contemporaneous impact on tax revenue, whereas tax increase has negative contemporaneous impact on GDP. 


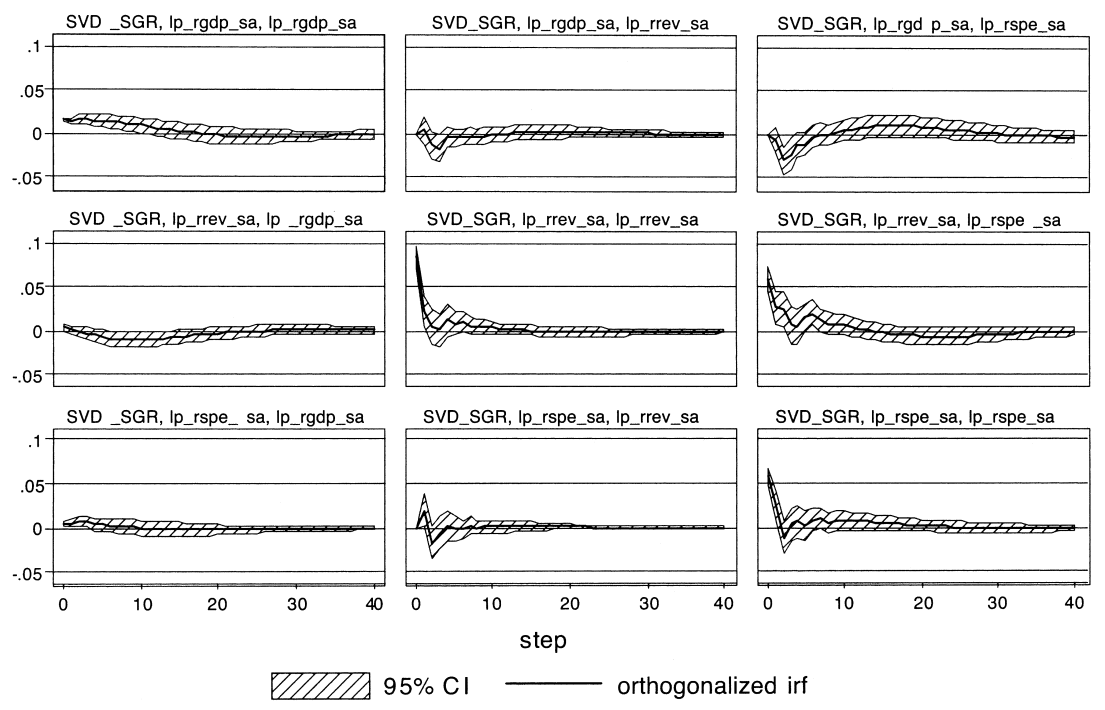

Fig. 3.2 Impulse-response functions of key variables (linearly detrended) by Cholesky ordering (in the order of tax revenue, expenditures, GDP)

Table 3.4 summarizes the estimation results of equation (4) with the data detrended by H-P filter. In this case, the responses of GDP to the impulses of tax revenue and the government spending are either very small or statistically insignificant. ${ }^{14}$ Figure 3.3 draws impulse-response functions for all the three variables.

In table 3.4 impulse responses of GDP have significantly positive signs for the first two quarters following a shock in tax revenue, while impulse responses to an expenditure shock hold significantly positive signs up to the second quarter and significantly negative signs for the sixth and seventh quarters. The positive effects of tax revenue increase as well as the negative effects of government expenditure increase on GDP are contrary to our general notion of Keynesianism. The accumulated fiscal multipliers of tax revenue and government expenditure range in $0.3 \sim 0.5$ and $0.03 \sim 0.05$ respectively. However, as in the previous case, these numbers are based on the imprecise estimates for $c_{1}$ and $c_{2}$. Therefore, the results in table 3.4 should not be heavily relied on, either.

The previous two cases of Cholesky decomposition are done in the order of tax revenue, government expenditure, and GDP. As for other possible combinations of shock ordering, we find the impulse-response functions diverging not only in their sign and size but also in their timing of effects and statistical significance.

14. For this case, the estimated sample standard deviations of innovation terms are $\left(e_{t}^{t}, e_{t}^{g}\right.$, $\left.e_{t}^{y}\right)=(0.077,0.056,0.013)$. 
Table 3.4

Impulse-response functions of interest variables (detrended by H-P filter) by Cholesky ordering (in the order of tax revenue, expenditure, GDP)

\begin{tabular}{lrrrrrr}
\hline Quarter & OIRF(1) & Lower(1) & Upper(1) & OIRF(2) & Lower(2) & Upper(2) \\
\hline 0 & 0.0053 & 0.0023 & 0.0082 & 0.0039 & 0.0011 & 0.0067 \\
1 & 0.0042 & 0.0005 & 0.0080 & 0.0038 & 0.0002 & 0.0074 \\
2 & 0.0033 & -0.0010 & 0.0077 & 0.0025 & -0.0017 & 0.0067 \\
3 & 0.0027 & -0.0019 & 0.0072 & 0.0020 & -0.0024 & 0.0065 \\
4 & 0.0022 & -0.0024 & 0.0067 & -0.0023 & -0.0068 & 0.0022 \\
5 & 0.0002 & -0.0031 & 0.0035 & -0.0025 & -0.0064 & 0.0013 \\
6 & -0.0013 & -0.0039 & 0.0014 & -0.0034 & -0.0068 & -0.0001 \\
7 & -0.0019 & -0.0044 & 0.0006 & -0.0036 & -0.0067 & -0.0006 \\
8 & -0.0017 & -0.0043 & 0.0009 & -0.0025 & -0.0051 & 0.0001 \\
9 & -0.0014 & -0.0039 & 0.0011 & -0.0016 & -0.0040 & 0.0009 \\
10 & -0.0009 & -0.0032 & 0.0013 & -0.0006 & -0.0030 & 0.0018 \\
\hline
\end{tabular}

Note: See table 3.3 notes.
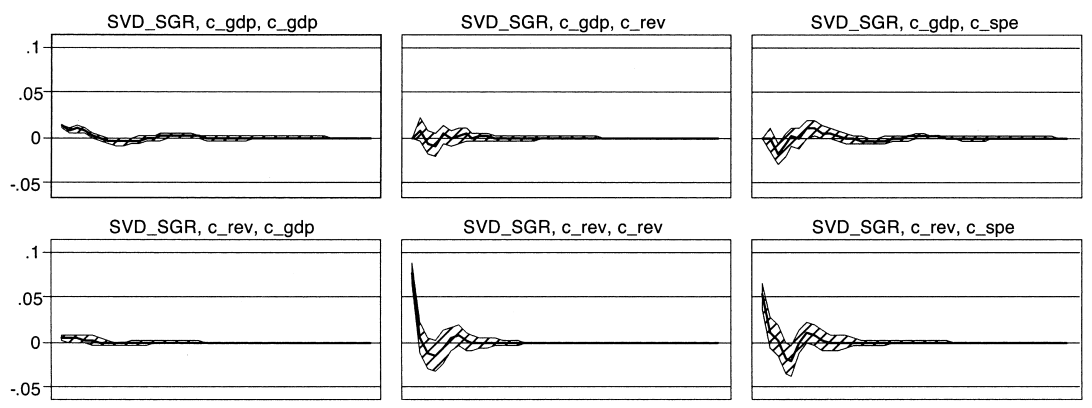

SVD_SGR, c_rev, c_rev

SVD_SGR, c_rev, c_spe
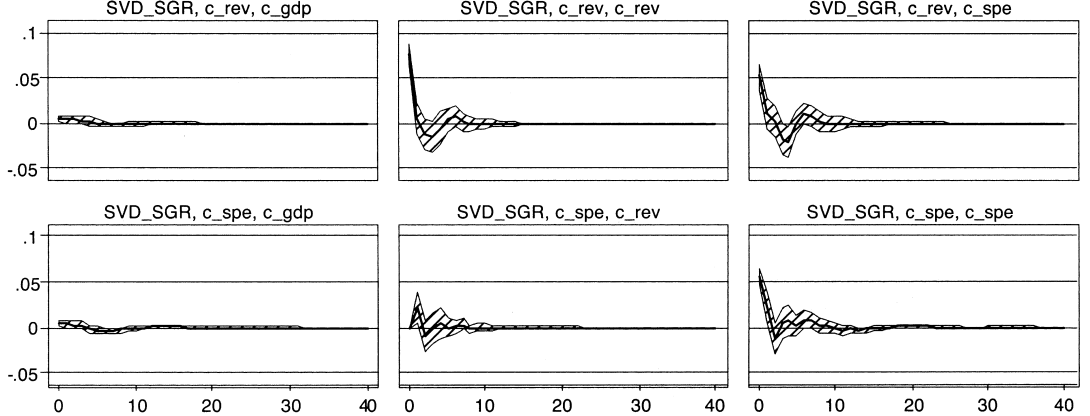

SVD_SGR, c_spe, c_rev

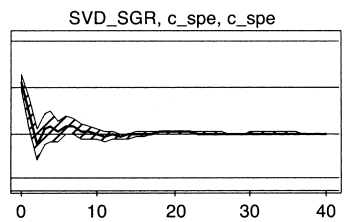

DIDZ 95\% Cl orthogonalized irf

Fig. 3.3 Impulse-response functions of interest variables (detrended by H-P filter) by Cholesky ordering (in the order of tax revenue, expenditure, GDP)

\section{Identification by Using Institutional Information ( B-P [2002])}

B-P (2002), based on equation (5), borrow institutional information on $\alpha_{3}$ from the calculation of GDP or tax bases elasticities of tax revenues. The additional restrictions, such as $\beta_{3}=a_{2}=0$ or $\beta_{3}=b_{1}=0$, seem rather arbitrary. While repeating the same procedure as in B-P (2002), we adopt the 
Table 3.5

Estimation of contemporaneous effect $\left(\alpha_{3}=1.09\right.$ and $\left.\beta_{3}=0\right)$

\begin{tabular}{llcll}
\hline & \multicolumn{1}{c}{$\gamma_{1}$} & $\gamma_{2}$ & $a_{2}\left(b_{1}=0\right)$ & $b_{1}\left(a_{2}=0\right)$ \\
\hline \multicolumn{5}{c}{ A Linearly detrended } \\
Estimate & $-0.086^{* * *}$ & $0.129^{* * *}$ & $0.659^{* * *}$ & $0.656^{* * *}$ \\
$t$-value & -2.73 & 4.03 & 7.90 & 7.90 \\
& \multicolumn{5}{c}{$0.655^{* * *}$} \\
Estimate & $-0.037^{* * *}$ & B. Detrended by H-P filter \\
$t$-value & -1.37 & $0.110^{* * *}$ & $0.603^{* * *}$ & 7.32 \\
\hline
\end{tabular}

***Significance level of less than 1 percent.

elasticities of tax revenues in Korea from Park and Park (2002) and assign $\alpha_{3}=1.09 .{ }^{15}$

Table 3.5 shows the estimation results of the contemporaneous effects using the residuals of the VAR systems in equation (2). The signs of contemporaneous effects of innovations in tax revenues and spending on the disturbance of $\operatorname{GDP}\left(\gamma_{1}\right.$ and $\left.\gamma_{2}\right)$ are consistent with our anticipation that tax increase reduces GDP while spending spurs it.

Table 3.6 compares the indirect contemporaneous effect of the automatic stabilization mechanism (ASM) and the direct contemporaneous effect of discretionary fiscal policy. The direct contemporaneous effects of fiscal innovations are measured by the estimates of $\gamma_{1}$ and $\gamma_{2}$. However, the changes in GDP influences back the tax revenue and the government spending in the form of $t_{t}$ and/or $g_{t}$, from which the ASM takes over. Summing up the direct and the indirect contemporaneous effects, we obtain the value of total contemporaneous effect following an innovation in the fiscal sector.

From table 3.6, we see that the positive indirect contemporaneous effects of the ASM dominates the negative direct impact of discretionary fiscal impulse in the case of tax shocks and $a_{2}=0$, while the direct effect of a spending shock is always greater than the indirect effect of the ASM followed.

In times of nonintervention, it is known that the built-in ASM smoothes out the fluctuation of a business cycle and reduces the need for government intervention. But in times of government intervention, the presence of the ASM works as friction against a policy maker, who intends to resize his or her fiscal programs for the purpose of controlling the business cycle. The results from table 3.6 indicate that the adjustment in tax has more to lose than to win, at least contemporaneously, once it is used, whereas that in the government spending still maintains its validity as intended.

15. Park and Park use the consolidated budget data from 1991 to 2002 (annual). They classify the current tax revenues in Korea in four groups (income tax, corporate tax, indirect tax, and social security contribution) and calculate the elasticity of tax revenue with respect to tax base for each group. $\alpha_{3}=1.09$ is the weighted average of the four tax elasticities by the proportion of tax revenues to GDP. 
Table 3.6

Decomposition of contemporaneous effects as a sum of the direct effect from discretionary policy and the indirect effect from automatic stabilization mechanism (ASM; $\alpha_{3}=1.09$ and $\beta_{3}=0$ )

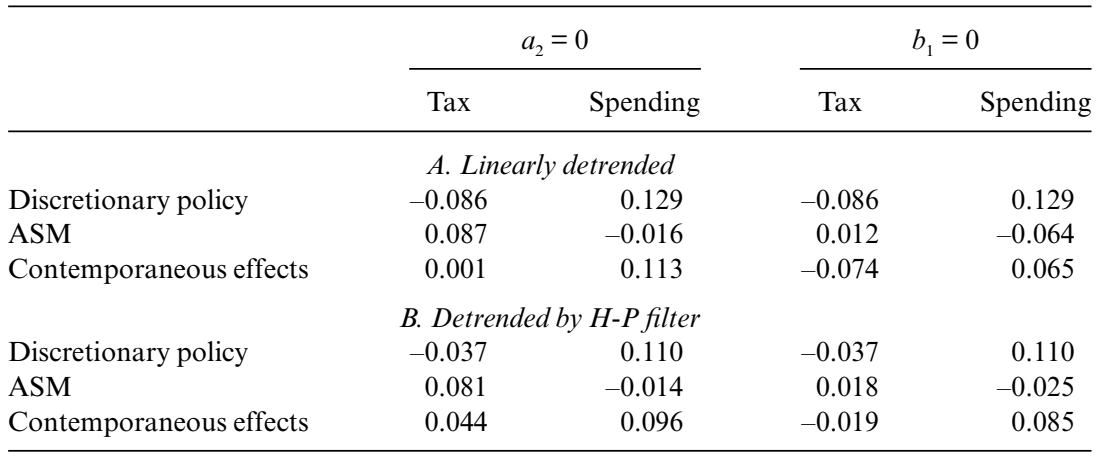

Figures 3.4-3.9 display the impulse-response functions of GDP with respect to tax revenue, government expenditure, and GDP, using the linearly detrended data, while figures 3.10-3.15 display the impulse-response functions using the data detrended by H-P filter. Comparing these two groups of figures, we infer that the linear time trend may detect (or exaggerate) the persistence of the fiscal shocks on GDP treatment of long-term trends, whereas H-P filter detrending may miss (or underestimate) the persistence. Especially, the persistence of tax revenue on GDP varies drastically depending on the treatment of long-term trends. ${ }^{16}$

Whichever detrending method may be taken, the figures of impulse responses show that the positive effect of expenditure policy is statistically significant only in the very short run (no longer than three quarters). On the other hand, the effect of tax increase is not significant in any case. Converted into fiscal multipliers, even the significant impulse responses have very small magnitudes less than 0.4 . Hence, the effectiveness of fiscal policy is not confirmed under B-P identification strategy. ${ }^{17}$

\section{Identification by Using "Expenditure within Revenue" Principle}

The third identification strategy (6) borrows the restrictions on $\beta_{1}(=0.598)$ from the government budget data in addition to $\alpha_{3}$, based on the perception of the "Expenditure within Revenue (EWR)" rule prevalent in the 1980s and 1990s in Korea. This identification strategy differs from B-P (2002) in that it allows contemporaneous duplex relation between $x_{t}$ and $g_{t}$.

16. Tax policy seems to have more persistent effect on GDP than revenue policy under the linear time trend, which tends to leave the nonlinear long-term trend. Accordingly, it remains a question whether the tax policy influences the long-term GDP growth or the nonlinear longterm trends of tax and GDP incidentally commove in a linear way.

17. Disregarding the 95 percent confidence interval and focusing on the fitted line of the impulse responses, we could have obtained the high value of accumulated fiscal multipliers in figure 3.4, figure 3.7, and figure 3.8. 


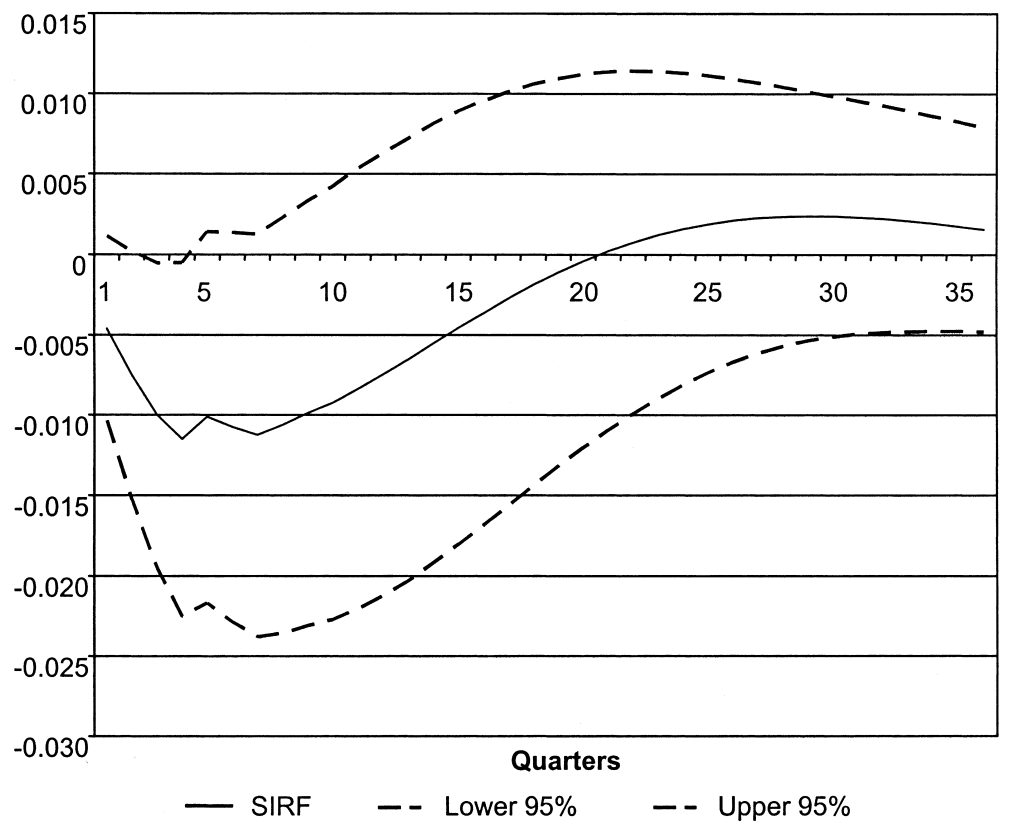

Fig. 3.4 Impulse responses of GDP to tax revenue estimated by B-P (2002; linearly detrended and setting $b_{1}=0$ )

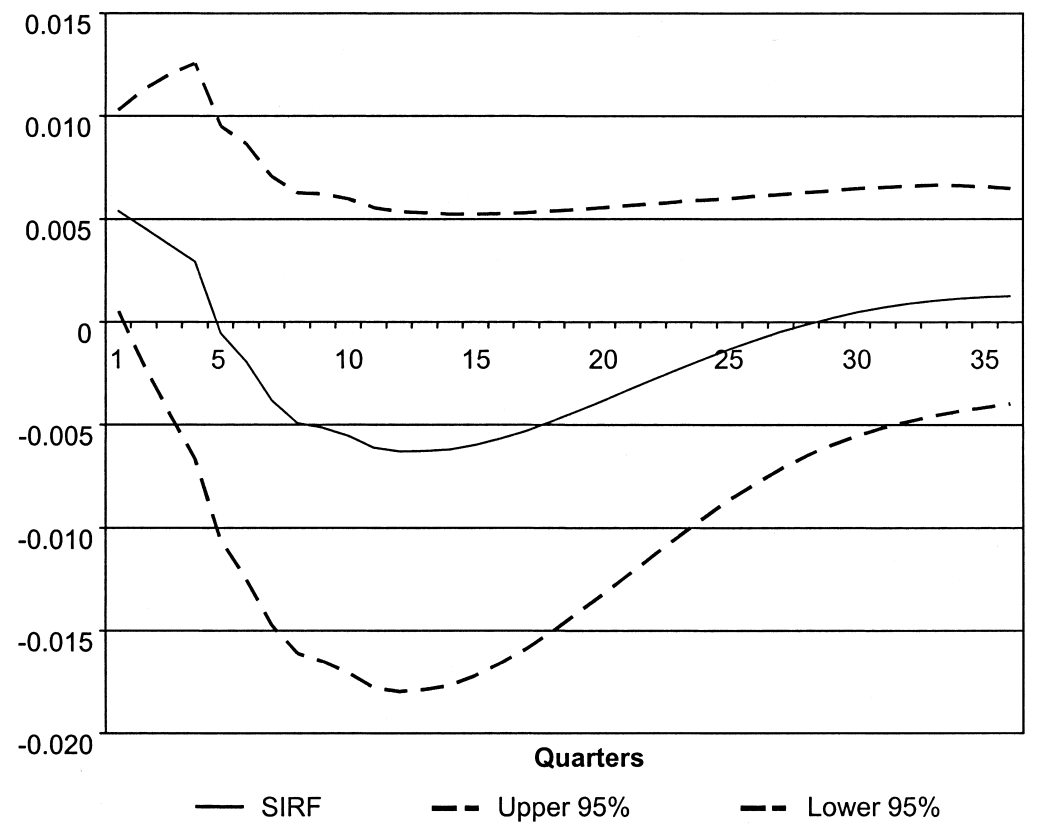

Fig. 3.5 Impulse responses of GDP to expenditure estimated by B-P (2002; linearly detrended and setting $b_{1}=0$ ) 


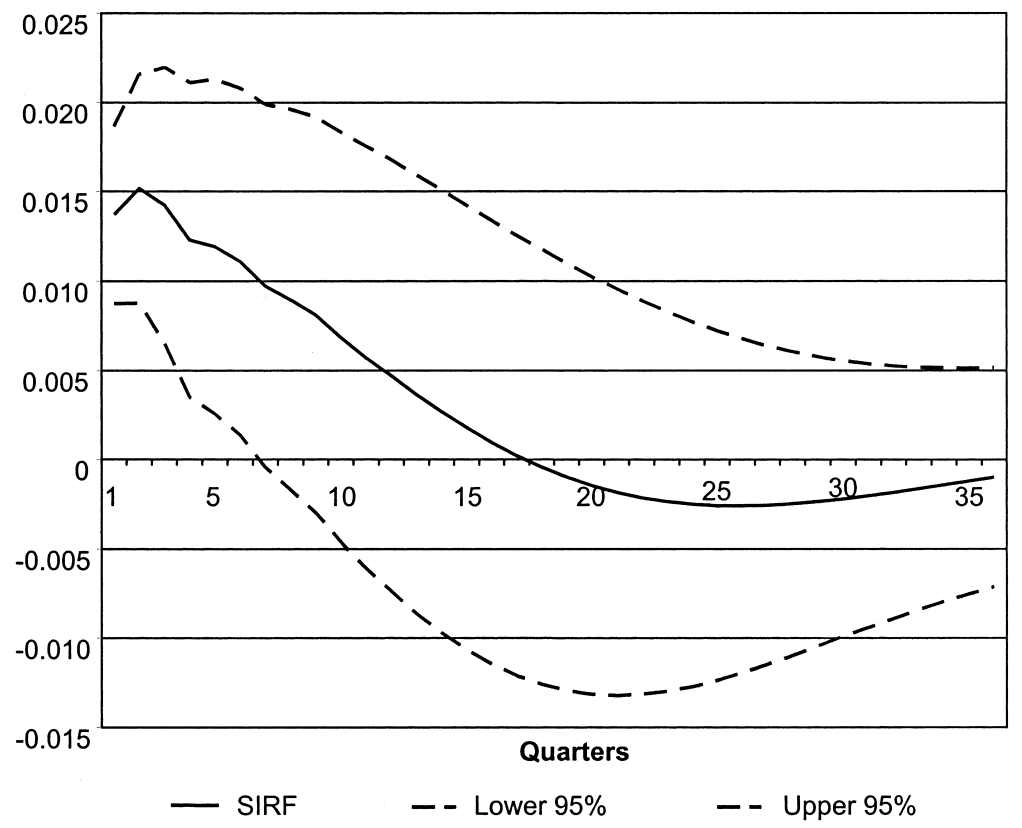

Fig. 3.6 Impulse responses of GDP on GDP estimated by B-P (2002; linearly detrended and setting $b_{1}=0$ )

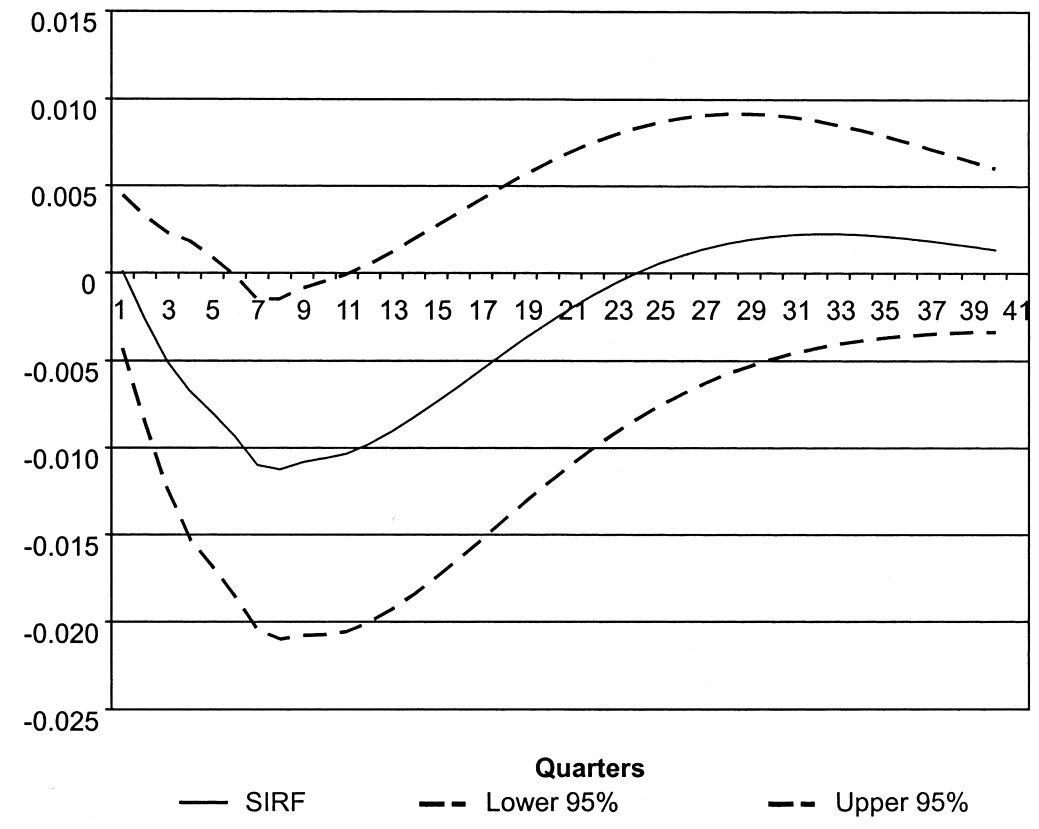

Fig. 3.7 Impulse responses of GDP to tax revenue estimated by B-P (2002; linearly detrended and setting $a_{2}=0$ ) 


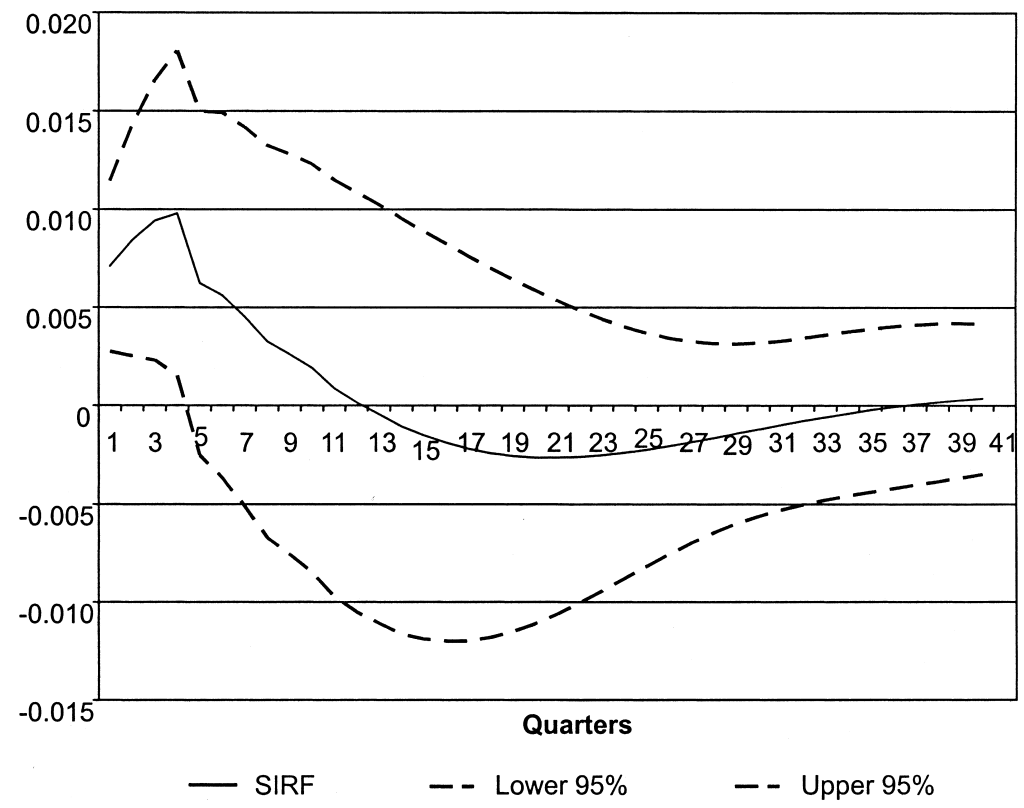

Fig. 3.8 Impulse responses of GDP to expenditure estimated by B-P (2002; linearly detrended and setting $a_{2}=0$ )

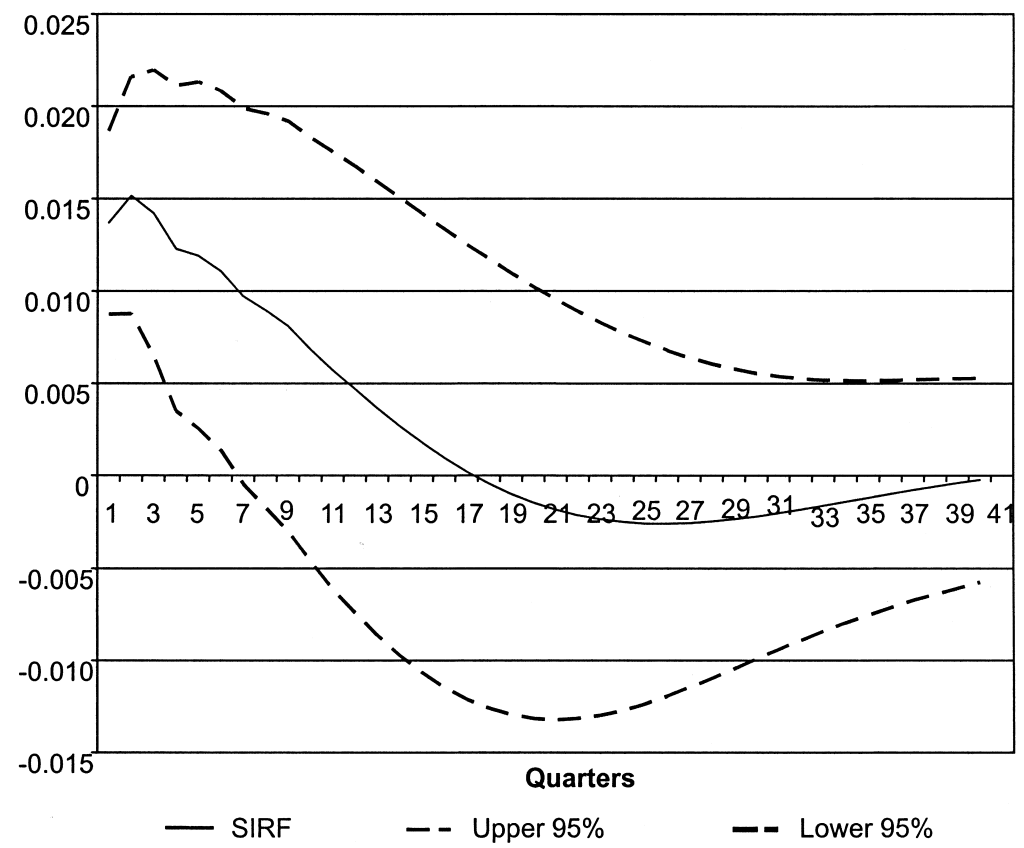

Fig. 3.9 Impulse responses of GDP on GDP estimated by B-P (2002; linearly detrended and setting $a_{2}=0$ ) 


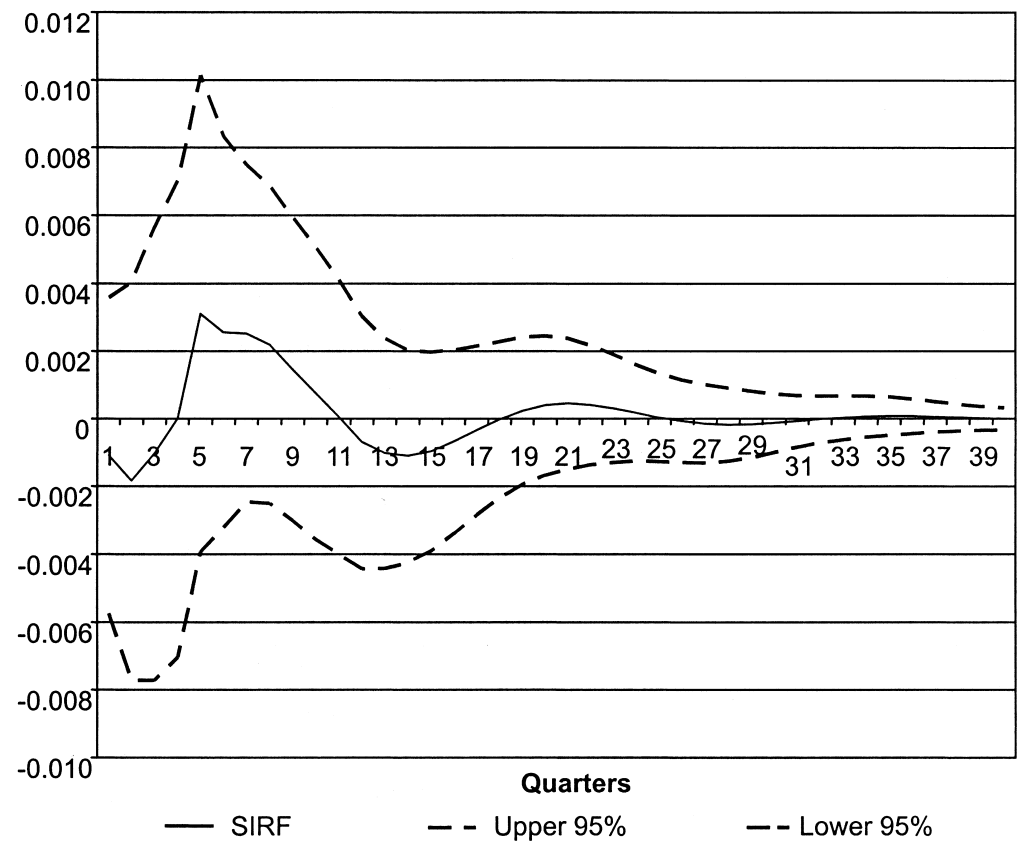

Fig. 3.10 Impulse responses of GDP to tax revenue estimated by B-P (2002; detrended by $\mathrm{H}-\mathrm{P}$ filter and setting $b_{1}=0$ )

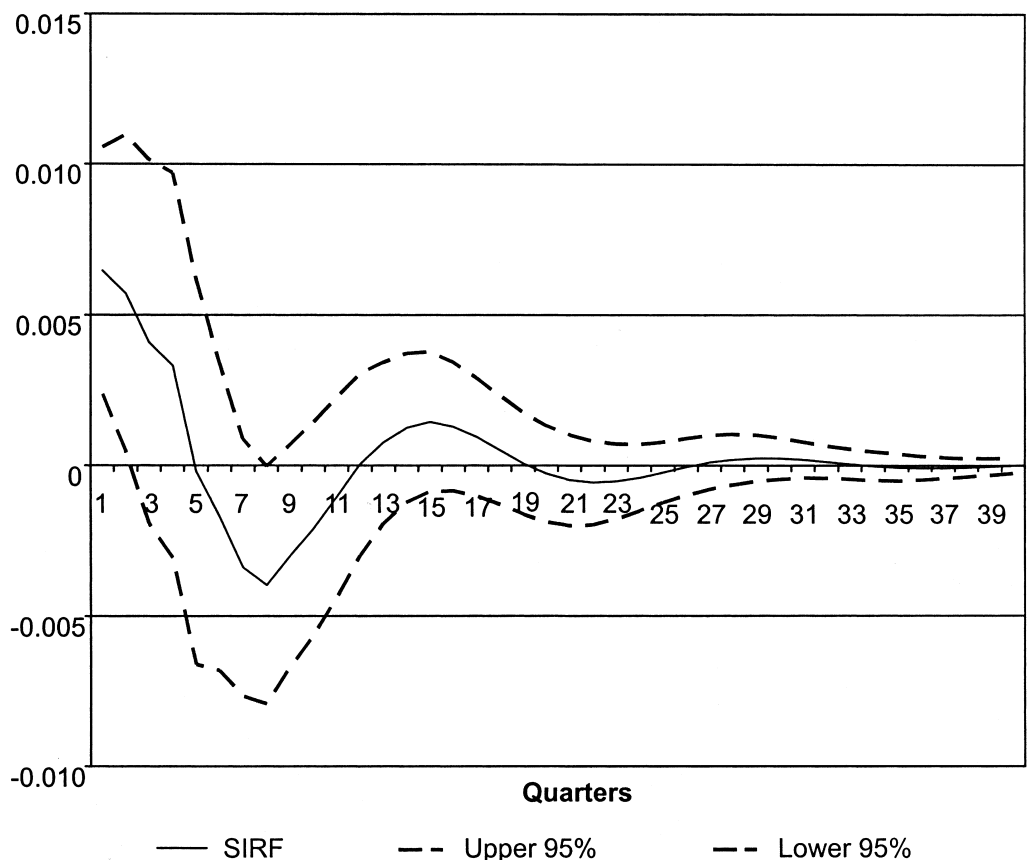

Fig. 3.11 Impulse responses of GDP to expenditure estimated by B-P (2002; detrended by $H-P$ filter and setting $b_{1}=0$ ) 


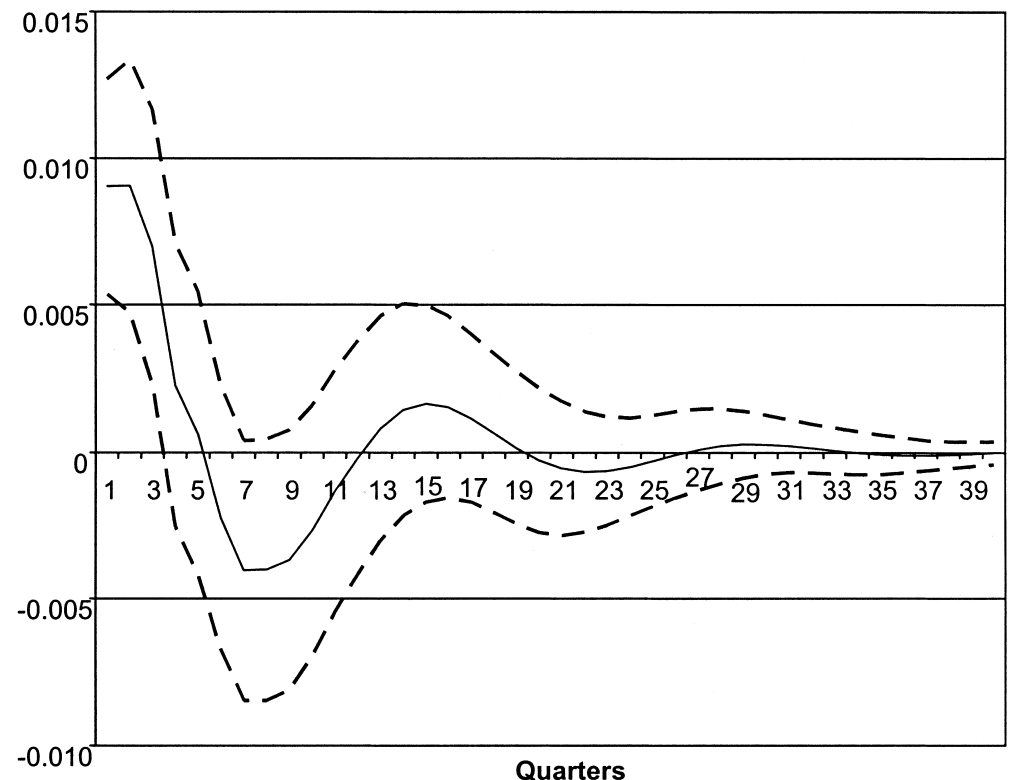

Quarters

- SIRF - - Lower $95 \%$ - - Upper $95 \%$

Fig. 3.12 Impulse responses of GDP on GDP estimated by B-P (2002; detrended by $\mathrm{H}-\mathrm{P}$ filter and setting $b_{1}=0$ )

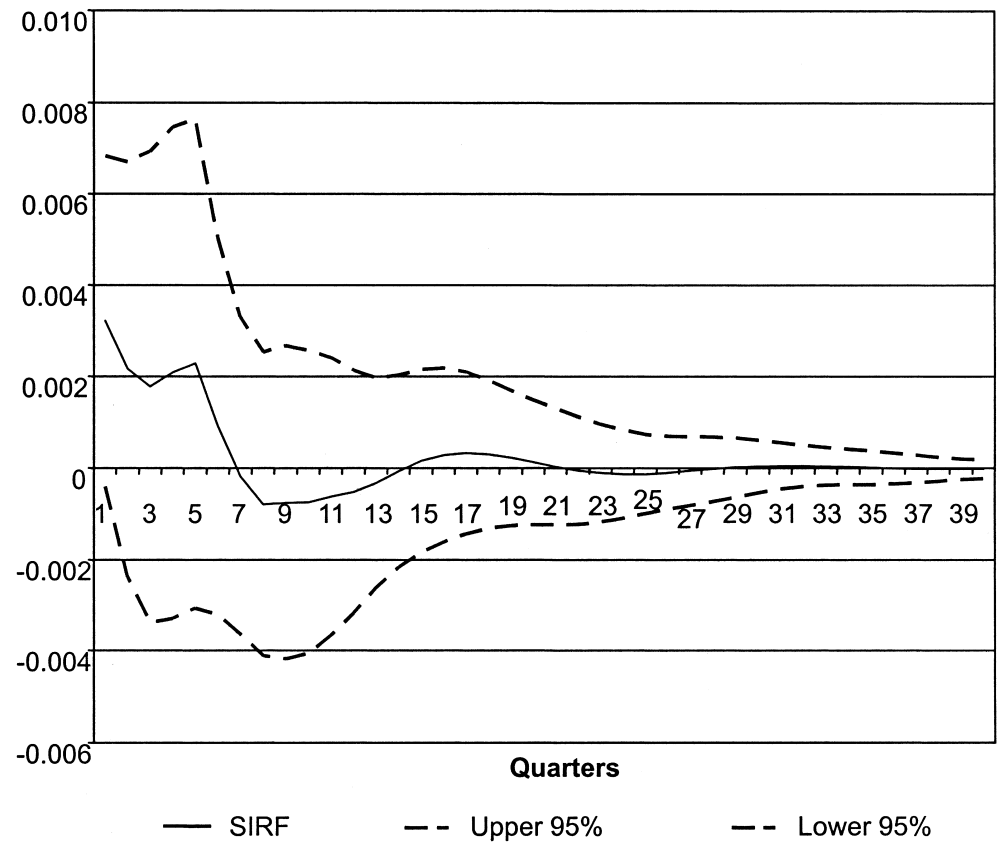

Fig. 3.13 Impulse responses of GDP to tax revenue estimated by B-P (2002; detrended by $\mathrm{H}-\mathrm{P}$ filter and setting $a_{2}=0$ ) 


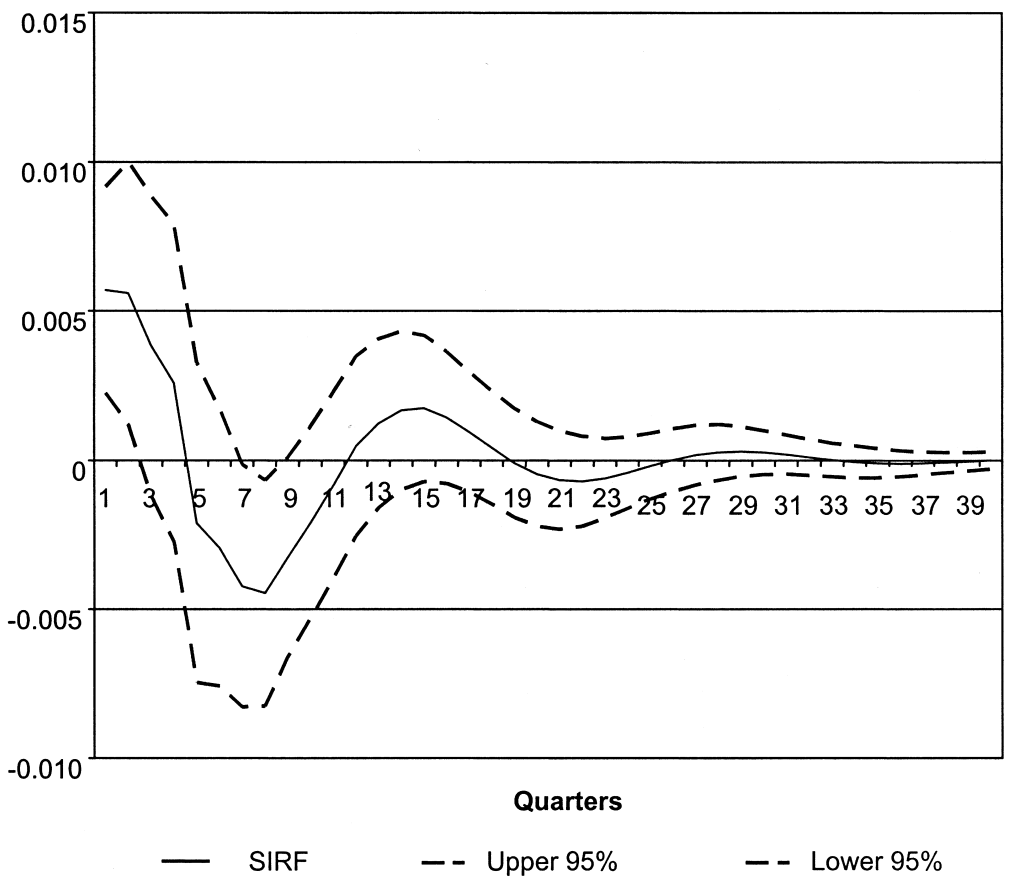

Fig. 3.14 Impulse responses of GDP to expenditure estimated by B-P (2002; detrended by $\mathrm{H}-\mathrm{P}$ filter and setting $a_{2}=0$ )

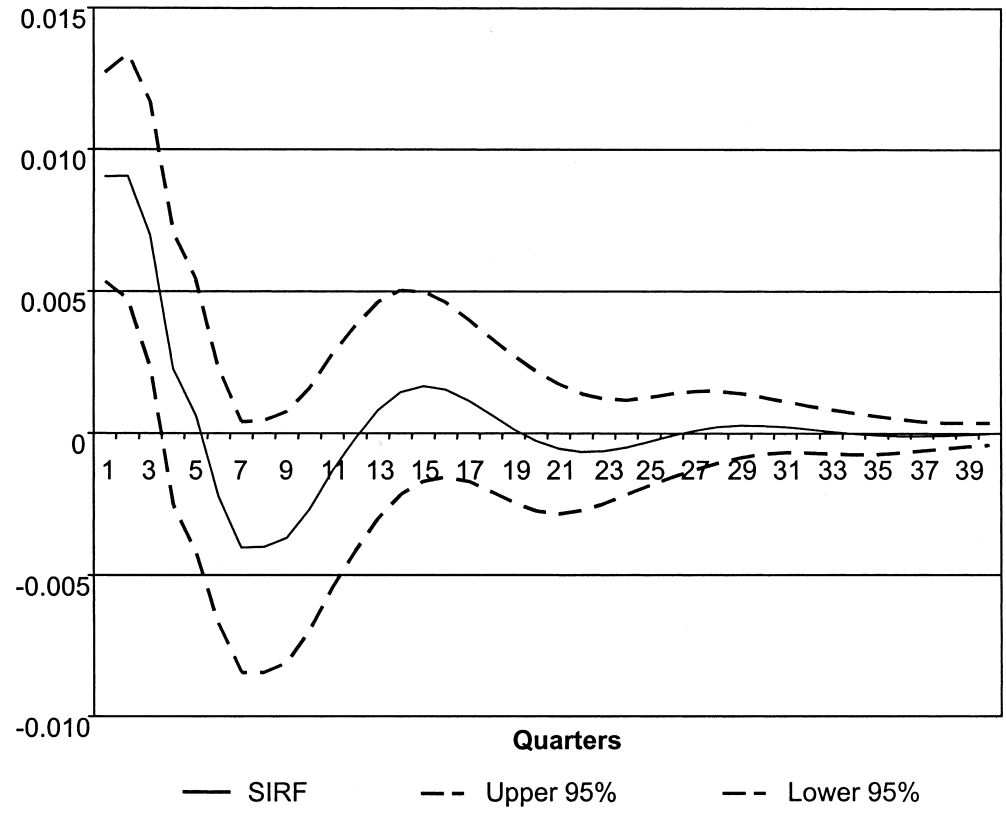

Fig. 3.15 Impulse responses of GDP on GDP estimated by B-P (2002; detrended by $H-P$ filter and setting $a_{2}=0$ ) 
Instead it restricts that the errors of the disturbances, $\left(e_{t}^{t}, e_{t}^{g}, e_{t}^{y}\right)$, should be orthogonal to each other.

Table 3.7 reports the estimated contemporaneous effects of fiscal disturbances on GDP. The signs of the direct contemporaneous effects $\left(\gamma_{1}\right.$ and $\gamma_{2}$ ) are consistent with those in table 3.5. For both detrending methods, the contemporaneous effects from the ASM are much greater than those of the discretionary tax shocks (table 3.8), which is opposite to the case of spending shocks. Such prevailing effect of the ASM, which works against the intended direction of discretionary revenue policy, is consistent with Keynesian wisdom that tax multiplier is smaller than that of spending.

Figures 3.16-3.18 draw the impulse responses of GDP to tax revenue, expenditure, and GDP with the linearly detrended data, and figures 3.193.21 draw the impulse responses with the data detrended by H-P filter. Some notable points from the figures are as follows. First, increasing spending has a significantly positive effect on GDP for the first 3 to 5 quarters regardless of a detrending method (though their magnitudes are also negligible when converted into fiscal multipliers). Second, tax increase has

Table 3.7

Estimation of contemporaneous effect $\left(\alpha_{3}=1.09, \alpha_{2}=0, \beta_{1}=0.598\right.$, $\left.\beta_{2}=0\right)$

\begin{tabular}{lcl}
\hline & \multicolumn{1}{c}{$\gamma_{1}$} & \multicolumn{1}{c}{$\gamma_{2}$} \\
\hline & A. Linearly detrended & \\
Estimate & $-0.056^{*}$ & $0.082^{* * *}$ \\
$t$-value & -1.84 & 2.67 \\
& B. Detrended by H-P filter & \\
Estimate & -0.014 & $0.075^{* *}$ \\
$t$-value & -0.55 & 2.86 \\
\hline
\end{tabular}

***Significance level of less than 1 percent.

**Significance level of less than 5 percent.

*Significance level of less than 10 percent.

Table 3.8 Decomposition of contemporaneous effects as a sum of the direct effect from discretionary policy and the indirect effect from automatic stabilization mechanism $\left(\mathrm{ASM} ; \alpha_{3}=1.09, \alpha_{2}=0, \beta_{1}=0.598, \beta_{2}=0\right)$

\begin{tabular}{lrr}
\hline & Tax & Spending \\
\hline \multicolumn{4}{c}{ A. Linearly } & detrended \\
Discretionary policy & -0.056 & 0.082 \\
ASM & 0.062 & -0.076 \\
Contemporaneous effects & 0.006 & 0.006 \\
\multicolumn{4}{c}{ B. Detrended by } & H-P filter \\
Discretionary policy & -0.014 & 0.075 \\
ASM rontemporaneous effects & 0.022 & -0.070 \\
Contem & 0.008 & 0.005 \\
\hline
\end{tabular}




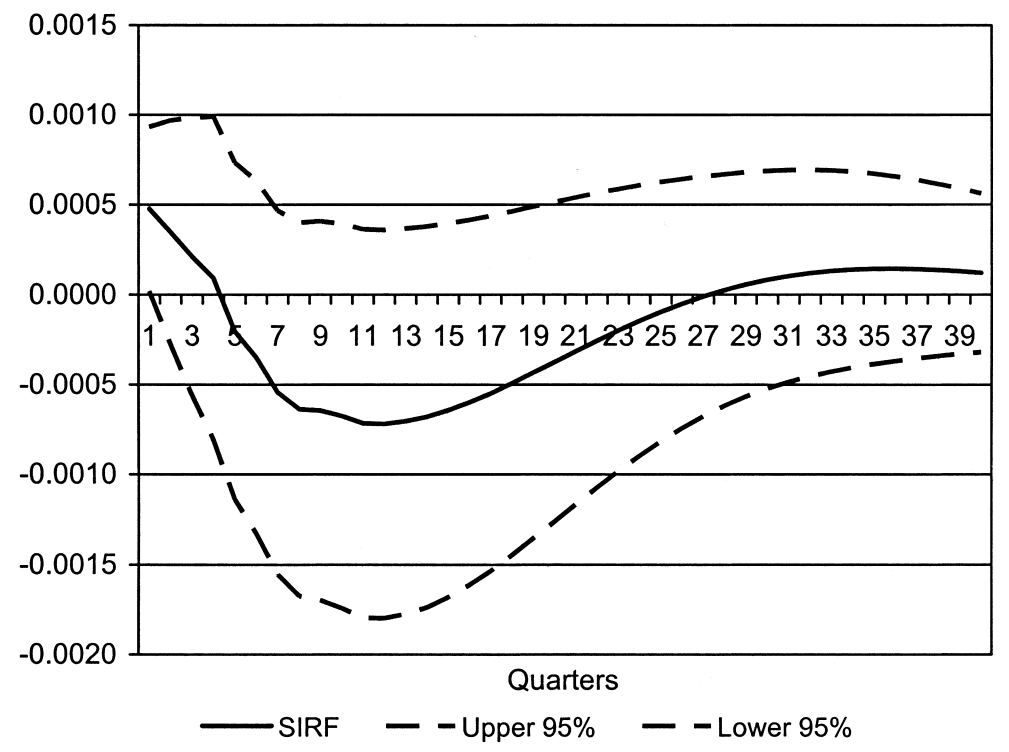

Fig. 3.16 Impulse responses of GDP to tax revenue estimated by alternative institutional identifying restrictions (linearly detrended)

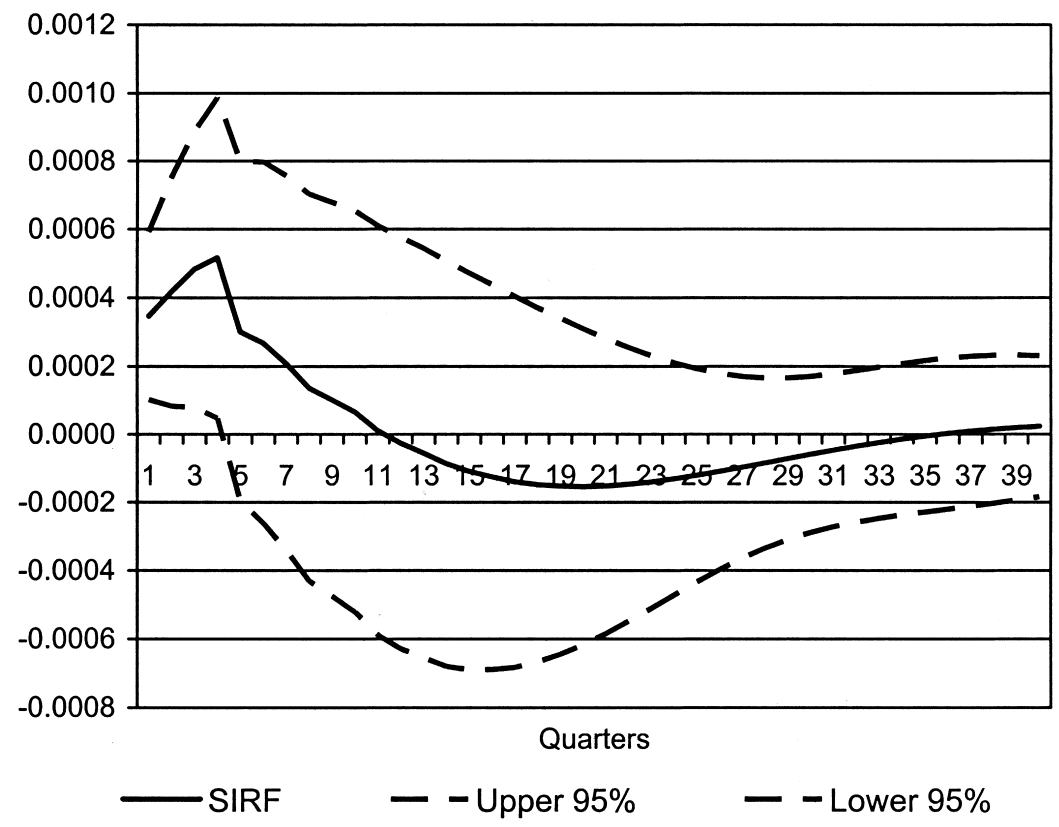

Fig. 3.17 Impulse responses of GDP to expenditure estimated by alternative institutional identifying restrictions (linearly detrended) 


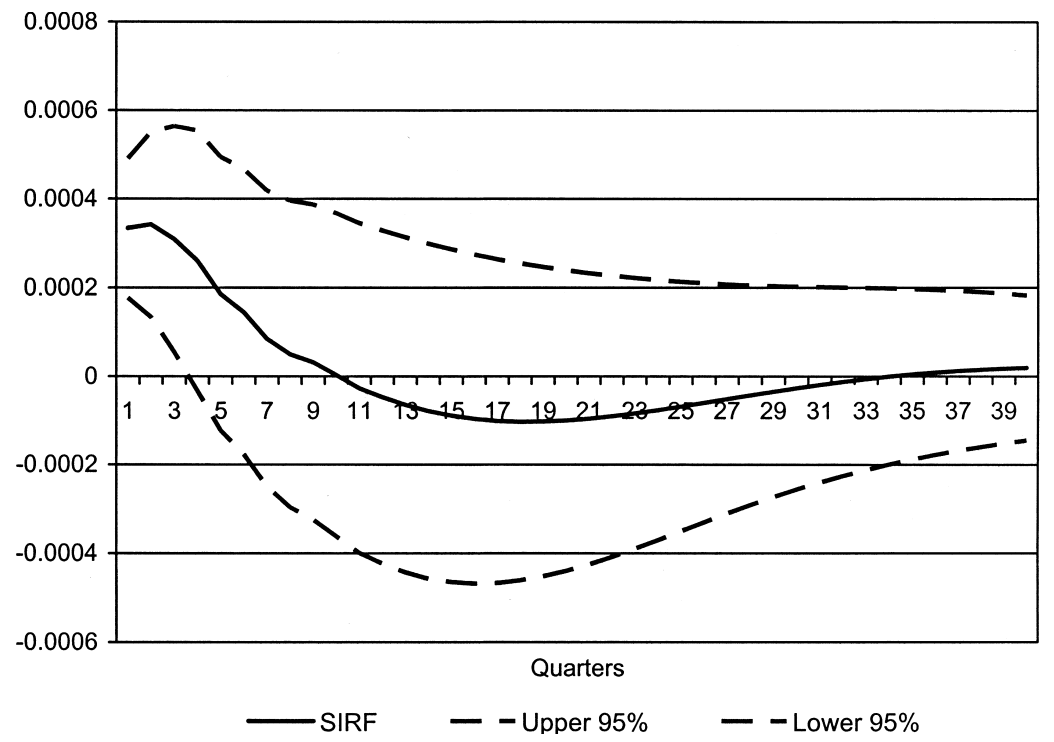

Fig. 3.18 Impulse responses of GDP on GDP estimated by alternative institutional identifying restrictions (linearly detrended)

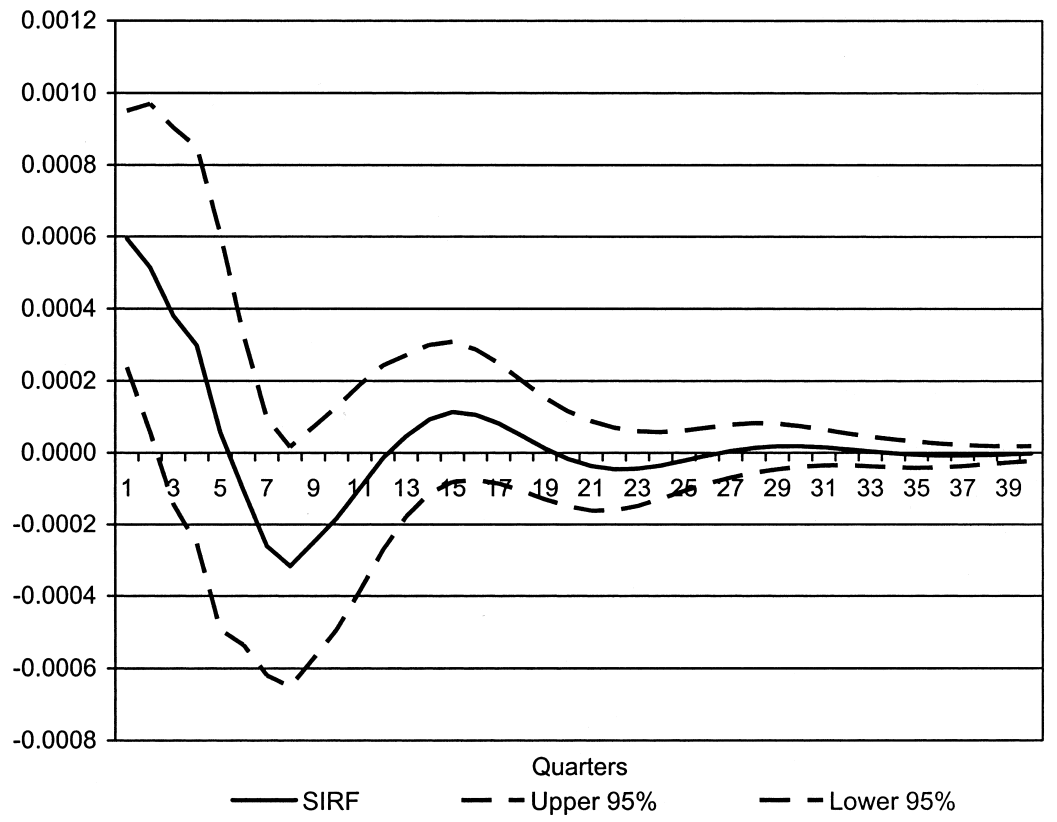

Fig. 3.19 Impulse responses of GDP to tax revenue estimated by alternative institutional identifying restrictions (detrended by $\mathrm{H}-\mathrm{P}$ filter) 


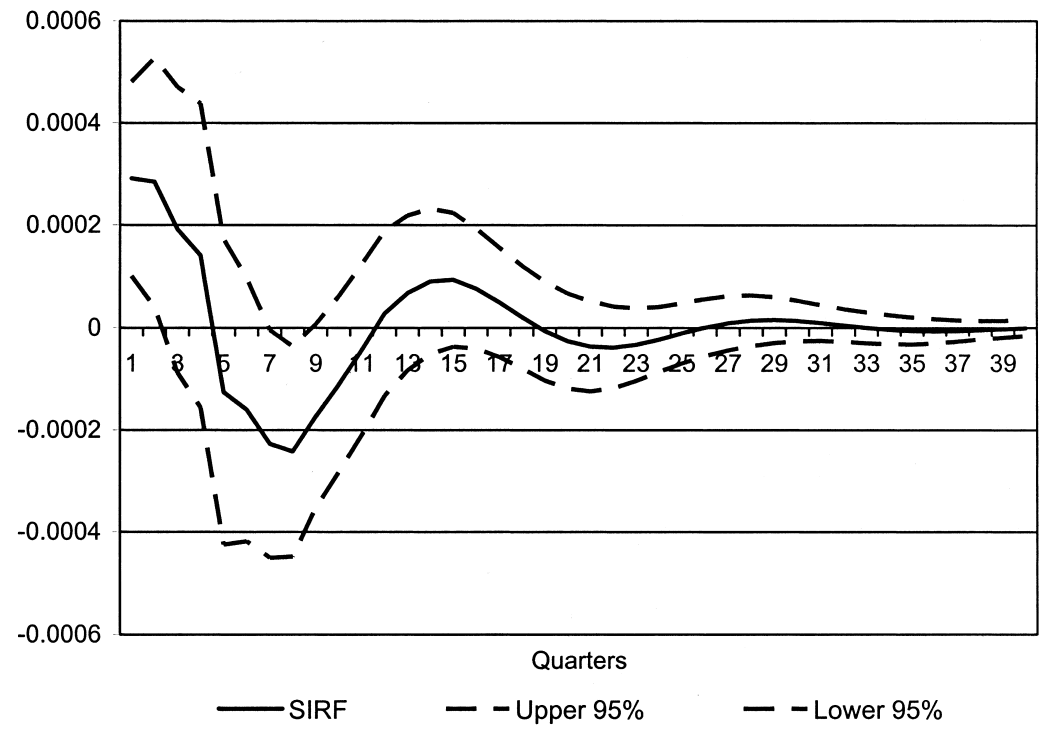

Fig. 3.20 Impulse responses of GDP to expenditure estimated by alternative institutional identifying restrictions (detrended by $\mathrm{H}-\mathrm{P}$ filter)

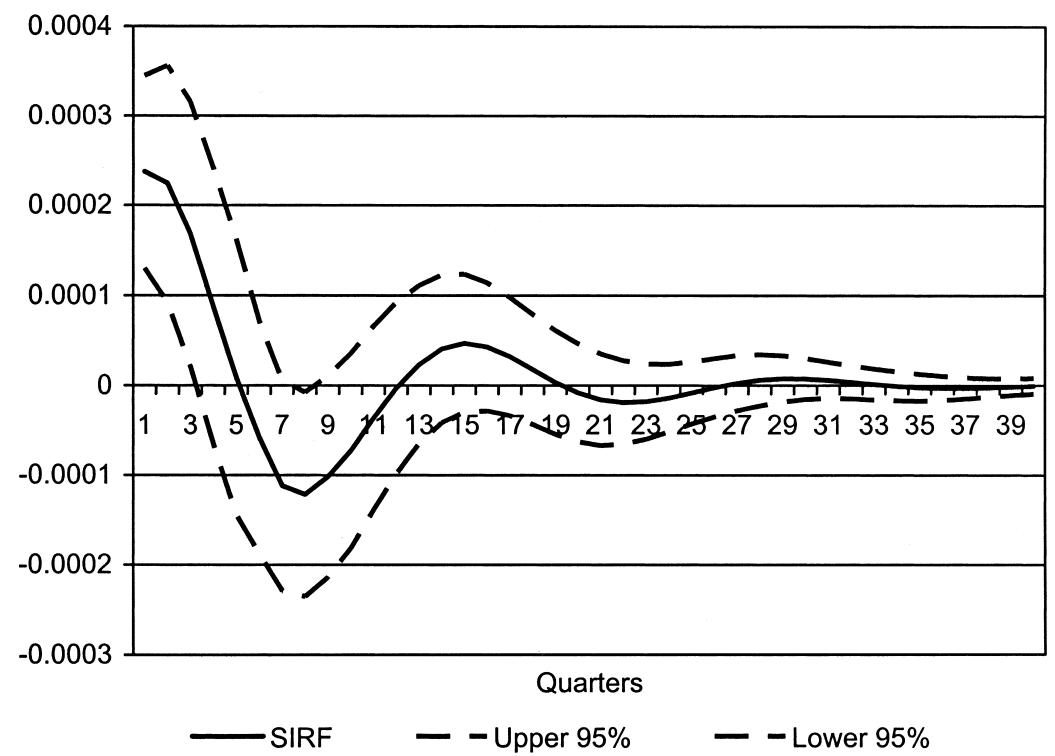

Fig. 3.21 Impulse responses of GDP on GDP estimated by alternative institutional identifying restrictions (detrended by $\mathrm{H}-\mathrm{P}$ filter) 
a positive effect (very short lived), which is opposite to our anticipation. As previously mentioned, it can be attributed to the dominant contemporaneous effect of the ASM. Furthermore, it seems that the persistence of the counteractive effect from the ASM dilutes the negative effect of tax increase on GDP over a long horizon, leading to insignificant fiscal impulses.

So far we have considered various identification strategies starting from usual Cholesky decomposition in this section. Their results show different predictions on the effects from discretionary fiscal policy not only in terms of magnitudes but also in terms of signs. Though most of them confirm that the expansionary fiscal stance (whether it is tax cut or spending spree) has expansionary effect on the economy, we cannot believe that this demonstrates the effectiveness of the fiscal policy considering most of the 95 percent significance intervals cover both negative and positive ranges.

\subsubsection{Results from 4 Variable VARs Allowing Outside Shocks}

In this section we check whether there exist omitted variables and if their inclusion would determine the signs of effects between fiscal variables and business cycle.

Considering the trade dependence of the Korean economy, we infer that shocks of foreign origination may have critical impacts on the Korean economy, which will result in different estimations of impulse-response functions. Hence, we select the per capita real GDP of US( $Y_{t}^{U S}$ in logarithms) and the real effective exchange rate of Korean currency (logarized REER) for the most critical omitted variables and we add these two variables to the estimation of (2) one by one. ${ }^{18}$ The importance of the U.S. economy in determining the growth path of the Korean economy is needless to say. REER is included because its time path has been very responsive to the past economic turmoils including the recent currency crisis. ${ }^{19}$

Shock-identification strategies for the new set of four-variable VAR systems take a dual approach, which maintains (4) through (6) among the existing three variables and requires Cholesky decomposition between a newly introduced variable for external shocks and the vector of the existing variables.

Table 3.9 summarizes the estimation results of the four-variable VAR systems in terms of elasticities (both one period and accumulated). ${ }^{20}$ The elas-

18. In addition to them, we try the Terms Of Trade (TOT) as an exogenous variable to equation (2). However, the previous results stay unchanged.

19. Following Ramey and Shapiro (1998), the VAR literature treats certain economic episodes with dummies. However, this way of identifying structural breaks is not appropriate for our analysis because the end point of the data set (2000 Q4) is not far enough from the starting point of the Korean currency crisis (1997 Q4). In this situation, REER can be substituted for a dummy of the currency crisis.

20. Divided by the proportion of government expenditure or revenue to GDP, these elasticities are easily converted into the fiscal multipliers (in the unit of Korean currency). Though it varies year by year, the proportion of government expenditure or revenue to GDP is approximately 25 to 30 percent. Thus, the fiscal multipliers will be approximately three to four times of the elasticities in table 3.9. 
Table 3.9

The elasticities of real GDP to the shocks from various sources

\begin{tabular}{|c|c|c|c|c|c|}
\hline Group & $\begin{array}{c}\text { Shock } \\
\text { identification }\end{array}$ & Elasticity & $\begin{array}{l}\text { External } \\
\text { shock }\end{array}$ & $\begin{array}{l}\text { Revenue } \\
\text { (tax) shock }\end{array}$ & $\begin{array}{l}\text { Expenditure } \\
\text { shock }\end{array}$ \\
\hline \multirow[t]{8}{*}{ I } & \multirow{2}{*}{$\begin{array}{l}\text { Cholesky } \\
\text { decomposition }\end{array}$} & One period & n.a. & n.a. & $0.086(0)$ \\
\hline & & Accumulated & n.a. & n.a. & $0.153(0 \sim 1)$ \\
\hline & \multirow{2}{*}{$\begin{array}{l}\mathrm{BP}(2002): \\
\quad a_{2}=0\end{array}$} & One period & n.a. & $0.043(1)$ & $0.137(2)$ \\
\hline & & Accumulated & n.a. & $0.081(0 \sim 1)$ & $0.3840(0 \sim 2)$ \\
\hline & \multirow{2}{*}{$\begin{array}{c}\mathrm{BP}(2002): \\
b_{1}=0\end{array}$} & One period & n.a. & $-0.170(3)$ & n.a. \\
\hline & & Accumulated & n.a. & $-1.745(0 \sim 13)$ & n.a. \\
\hline & \multirow{2}{*}{ EWR } & One period & n.a. & $-0.131(7)$ & $0.094(1)$ \\
\hline & & Accumulated & n.a. & $-1.492(0 \sim 17)$ & $0.171(0 \sim 1)$ \\
\hline \multirow[t]{8}{*}{ II } & \multirow{2}{*}{$\begin{array}{l}\text { Cholesky } \\
\text { decomposition }\end{array}$} & One period & n.a. & n.a. & $0.069(0)$ \\
\hline & & Accumulated & n.a. & n.a. & $0.135(0 \sim 1)$ \\
\hline & \multirow{2}{*}{$\begin{array}{l}\mathrm{BP}(2002): \\
\quad a_{2}=0\end{array}$} & One period & n.a. & $0.042(0)$ & $0.107(0)$ \\
\hline & & Accumulated & n.a. & $0.042(0)$ & $0.199(0 \sim 1)$ \\
\hline & \multirow{2}{*}{$\begin{array}{c}\mathrm{BP}(2002): \\
b=0\end{array}$} & One period & n.a. & $-0.044(0)$ & $0.079(0)$ \\
\hline & & Accumulated & n.a. & $-0.078(0 \sim 1)$ & $0.151(0 \sim 1)$ \\
\hline & \multirow[t]{2}{*}{ EWR } & One period & n.a. & n.a. & $0.078(0)$ \\
\hline & & Accumulated & n.a. & n.a. & $0.152(0 \sim 1)$ \\
\hline \multirow[t]{8}{*}{ III } & \multirow{2}{*}{$\begin{array}{l}\text { Cholesky } \\
\text { decomposition }\end{array}$} & One period & $-0.283(2)$ & n.a. & $0.068(0)$ \\
\hline & & Accumulated & $-1.316(0 \sim 5)$ & n.a. & $0.068(0)$ \\
\hline & \multirow{2}{*}{$\begin{array}{l}\mathrm{BP}(2002): \\
\quad a_{2}=0\end{array}$} & One period & $-0.283(2)$ & $0.053(0)$ & $0.097(0)$ \\
\hline & & Accumulated & $-1.316(0 \sim 5)$ & $0.249(0 \sim 3)$ & $0.097(0)$ \\
\hline & $\mathrm{BP}(2002)$ & One period & $-0.283(2)$ & $-0.125(2)$ & n.a. \\
\hline & \multirow{3}{*}{$\begin{array}{l}\quad b_{1}=0 \\
\text { EWR }\end{array}$} & Accumulated & $-1.317(0 \sim 5)$ & $-1.848(0 \sim 24)$ & n.a. \\
\hline & & One period & $-0.277(2)$ & n.a. & $0.070(0)$ \\
\hline & & Accumulated & $-1.102(0 \sim 4)$ & n.a. & $0.070(0)$ \\
\hline \multirow[t]{8}{*}{ IV } & \multirow{2}{*}{$\begin{array}{l}\text { Cholesky } \\
\text { decomposition }\end{array}$} & One period & $-0.203(1)$ & $0.043(0)$ & $0.071(0)$ \\
\hline & & Accumulated & $-0.659(0 \sim 3)$ & $0.043(0)$ & $0.071(0)$ \\
\hline & \multirow{2}{*}{$\begin{array}{c}\mathrm{BP}(2002): \\
\quad a=0\end{array}$} & One period & $-0.203(1)$ & $0.060(0)$ & $0.095(0)$ \\
\hline & & Accumulated & $-0.659(0 \sim 3)$ & $0.116(0 \sim 1)$ & $0.095(0)$ \\
\hline & $\mathrm{BP}(2002)$ & One period & $-0.203(1)$ & $-0.048(1)$ & $0.072(0)$ \\
\hline & \multirow{3}{*}{$\begin{array}{l}\quad b_{1}=0 \\
\text { EWR }\end{array}$} & Accumulated & $-0.659(0 \sim 3)$ & $-0.142(0 \sim 3)$ & $0.072(0)$ \\
\hline & & One period & $-0.198(1)$ & n.a. & $0.072(0)$ \\
\hline & & Accumulated & $-0.638(0 \sim 3)$ & n.a. & $0.072(0)$ \\
\hline
\end{tabular}

Note: All numbers in parentheses denote the corresponding quarter(s) to the elasticities on the left.

ticities are calculated by dividing the impulse-response functions by the standard deviations of the corresponding orthogonalized disturbance terms $e_{t}^{x}$, $e_{t}^{t}, e_{t}^{g}$, and $e_{t}^{y}$. Then the elasticities are recorded only when their signs are statistically significant in 95 percent confidence intervals. Groups (I) and (III) describe the results from running the VAR model with the linearly detrended data while groups (II) and (IV) deal with the data detrended by H-P filter. In the meantime, groups (I) and (II) include the real per capita GDP of US in log scale as a measure for the exogenous shock whereas groups (III) and (IV) use the logarized REER instead. In each group, the four-identification strategies, which are defined in the previous section, are dealt with. 
Compared with the previous three-variable VAR setup, the following points are notable in the results from the four-variable VAR. First, the significance of fiscal stimulus in boosting the economy has been enhanced overall regardless of the origination of the shock (either from the revenue or expenditure of the government). The increased significance of the fiscal impact can be attributed to the inclusion of the new variables (real per capita GDP of the United States and REER), which eliminate noises in the real per capita GDP of Korea.

Second, however, the magnitudes of the fiscal multipliers (which will be approximately 3 to 4 times of the elasticities) still remain small. Out of the 16 cases in table 3.7 , only three cases report the accumulated fiscal multipliers greater than 1 for a revenue shock and one case for an expenditure shock. ${ }^{21}$ Since these four exceptions deal with the linearly detrended data in common, it is inferred that the linear detrending may not be satisfactory to catch the nonlinear time trend of the real GDP. Combined with the linear detrending, it seems that the B-P (2002) identification strategy of setting $b_{1}=0$ emphasizes or exaggerates the transmission channels of a revenue shock.

Third, the persistence of fiscal stimuli is very short lived and cannot last longer than three quarters, except the three cases, all of which respond to a revenue shock. This persistence issue also seems to be linked to the selection of a detrending method.

Summing up, we see that the effectiveness of fiscal policy is significantly enhanced by introducing external shocks. However, in most cases the magnitudes of the fiscal multipliers and the duration of effectiveness are small or short lived, which are violated only when the linear detrending is adopted.

\subsubsection{Robustness of the Results to Other Variations in Specification}

The previous tested models are based on several restrictions, which are, we may suspect, possible causes of driving fiscal policy ineffectiveness. Among the restrictions, we are particularly interested in comprehending whether the selection of different lag orders, sample periods and filters as well as differencing some nonstationary variables, would confirm the effectiveness of fiscal policies.

First, we elect other criteria of lag orders. Previously, lag orders were selected by Akaike's Information Criteria (AIC). According to Lutkepohl (1993), the Bayesian Information Criteria (BIC) provides consistent estimates of the true lag order, whereas minimizing the AIC tends to overestimate the true lag order. The use of BIC to the Korean data suggests the lag

21. The arbitrarily set criterion for the accumulated fiscal multiplier is 1 . To maintain the budget balance after a fiscal expansion, the accumulated fiscal multiplier should exceed $1 / \tau(\tau=$ Tax_revenue/GDP), so called a balanced budget fiscal multiplier. Considering that $\tau \approx 0.25$ in Korea, the balanced budget fiscal multipliers should be about four. In table 3.4 , only three cases of revenue shocks report fiscal multipliers greater than four. For the rest of the cases fiscal expansion will aggravate the fiscal consolidation. 
of one, which is much smaller than the lag of four prescribed by AIC. Thus, we run the previously defined VAR setup with the reduced lag of one. However, these results also fail in confirming the effectiveness of fiscal policy.

Second, we introduce a dummy variable, which discerns the sample periods in two parts - before and after a currency crisis in late 1997. Even with the currency crisis dummy included, the effectiveness of fiscal policies cannot be significantly identified. ${ }^{22}$

Third, we adopt the Baxter and King's (1995) band pass filter instead of the H-P filter. The replacement of the detrending filter does not change the results of policy ineffectiveness. ${ }^{23}$

Fourth, in order to handle the nonstationarity of some variables, we take a routine measure of differencing all the variables or the real GDP only. Another option we choose is to investigate possible cointegration among the series and take a vector error correction form accordingly (Hamilton 1994). However, in either of them expansionary effects of fiscal stimuli are not confirmed.

\subsection{Concluding Remarks}

Summing up, our paper has shown that the effectiveness of fiscal policy is not significantly identified in Korea regardless of policy measures, tax reduction, or spending increase, or of methods of identifying shocks. ${ }^{24}$ Though significantly identified in some cases, the effect from the fiscal policy is either very small in magnitude or it phases out very quickly or it is caused by linear detrending. ${ }^{25}$ Such a low contribution of fiscal policy in economic stabilization provides many points to ponder in steering the future research on this issue. ${ }^{26}$

There are various ways of explaining the low performance of fiscal policy as a vehicle of boosting Korean economy. The first and easiest guess would be to accept the new classical argument. However, the question of

22. The BOK data set ends in the fourth quarter of 2000 and the number of observations after the currency crisis is very small. Accordingly, we compare the results from the consolidated budget data, which cover the period from 1994 to 2005 Q2 for cross-check.

23. In this case the confidence intervals are not shrinking along the passage of time.

24. Lee and Sung (2005) compare the estimators for the fiscal responsiveness of Korea to GDP shocks from OLS and IV estimation, and they report that both estimators are almost identical. Their results, mainly intended to eliminate the estimation bias for the fiscal responsiveness, can be interpreted to imply indirectly that fiscal expansion has no substantial effect on GDP.

25. In applying Cholesky decomposition, there are some cases in which the substantial effects of fiscal stimuli are significantly identified. Even in those cases, the estimates for the fiscal multipliers are based on the imprecise identification of contemporaneous relations among the shocks. Remember that in the estimation of the four variable SVARs, all the four cases, which have fiscal multipliers greater than one, use the linearly detrended data.

26. The use of consolidated budget data instead of the BOK data cannot support the effectiveness of fiscal policy, either. 
why the effectiveness of fiscal policy that is confirmed in other countries is refuted in the case of Korea still remains unsolved. ${ }^{27}$

The second guess is that there may not exist one-to-one correspondence between fiscal stance and the transition of a business cycle, such as matching fiscal expansion with booming or fiscal tightening with landing. In other words, there may be nonlinearity between fiscal measures and business cycles. Or there may exist an omitted and unobservable variable, the value of which changes the relationship between the fiscal variables and GDP. In such circumstances, the VAR models would not be able to detect the effectiveness of fiscal policy even if it is effective. ${ }^{28}$

Anyway, our paper comes to the findings, which are exactly opposite to the generally accepted Keynesian theory. Even so, it is still too early to replace it with the new classical theory. For example, Ricardian equivalence is an example of fiscal policy ineffectiveness. It does not cover all the transmission channels of fiscal policies, which our VAR setup evaluates in sum. In contrast, our setup does not identify exactly how the Ricardian equivalence argument works in an economy. Therefore, based on the achievements made by this paper, it is more desirable to continue our research in both of the following directions: verifying other possible transmission mechanisms of fiscal policies theoretically and comparing jointly their magnitudes of influence on the macro economy empirically.

\section{References}

Agenor, P-R., C. J. McDermott, and E. S. Prasad. 1999. Macroeconomic fluctuations in developing countries: Some stylized facts. IMF Working Paper 99/35. Washington, DC: International Monetary Fund.

Baxter, M., and King, R. 1995. Measuring business cycles: Approximate band-pass filters for economic time series. NBER Working Paper no. 5022. Cambridge, MA: National Bureau of Economic Research.

Becker, T. 1997. An investigation of Ricardian equivalence in a common trends model. Journal of Monetary Economics 39 (3): 405-31.

27. For one of pretests, we have done cross-country cross-sectional comparisons using World Development Indicators (by World Bank) as a measure to detect the effectiveness of fiscal policy. The result shows that the higher the government sector takes the portion in the aggregate economy the more stable the economy will be. In contrast, it also shows that the fluctuation of fiscal size doesn't have much to do with economic stabilization. Intuition behind this seemingly contradictory phenomenon is that the size of the government sector contributes to economic stability not because it can control business cycles but because it crowds out the private sector, which is more volatile than the government sector.

28. As another pretest, we ran a VAR model consisting of the estimated conditional volatilities of the growth rates in fiscal expenditures, tax revenues, and per capita real GDP in order to verify the stabilization effect of fiscal policies. The results showed that the increased volatility of fiscal expenditure growth alleviates the volatility of the GDP growth rate, which even partially supports this conjecture. 
Blanchard, O. J., and R. Perotti. 2002. An empirical characterization of the dynamic effects of changes in government spending and taxes on output. Quarterly Journal of Economics 117:1329-68.

Choi, Jong-Soo. 2002. An empirical analysis on the Barro-Ricardo equivalence hypothesis. Korean Journal of Public Economics 7 (1)

De Castro, F. 2004. The macroeconomic effects of fiscal policy in Spain. Applied Economics 38 (May): 913-24.

De Castro, F., and P. Hernandez de Cos. 2006. The economic effects of exogenous fiscal shocks in Spain: A SVAR approach. European Central Bank Working Paper no. 647.

Edelberg, W., M. Eichenbaum, and J. Fisher. 1999. Understanding the effects of shocks to government purchases. Review of Economic Studies: 166-206.

Fatas, A., and I. Mihov. 2000. The effects of fiscal policy on consumption and employment: Theory and evidence. INSEAD, mimeo.

Favero, C. 2002. How do European monetary and fiscal authorities behave? CEPR Working Paper no. 3426.

Feldstein, M. 1982. Government deficits and aggregate demand. Journal of Monetary Economics 9:1329-68.

Hamilton, J. 1994. Time series analysis. Princeton, NJ: Princeton University Press.

Hemming, R., M. Kell, and S. Mahfouz. 2002. The effectiveness of fiscal policy in stimulating economic activity - A review of the literature. IMF Working Paper. 02/208. Washington, DC: International Monetary Fund.

Hoppner, F. 2002. Fiscal policy and automatic stabilizers: A SVAR perspective. Institute for International Economics, University of Bonn Lennestr.

Kim, Seong-Suhn. 1997. Relative economic effects of sectoral government expenditures on consumption, investment and income. The Korean Journal of Public Finance 12 (1).

. 2003. A study on the structural change of fiscal policy after Korean currency crisis. Quarterly Economic Analysis 9 (4).

-2005. A comparison study on the fiscal spending effects to income, price money between pre- and post-currency crisis periods in Korea. The Korean Journal of Public Finance 20 (1).

Koh, Y. 2002. Public expenditure management in Korea. Mimeo.

Kormendi, R. 1983. Government debt, government spending and private sector behavior. American Economic Review73 (5): 994-1010.

Lee, I., and G. Kim. 2004. Economic effects of fiscal policy and tasks toward sound public finance. Korean Journal of Public Economics 9:253-94.

Lee, Y., and T. Sung. 2005. Fiscal policy, business cycles, and economic stabilization: Evidence from industrial and developing countries. Mimeo.

Lutkepohl, H. 1993. Introduction to multiple time series analysis, 2nd ed. New York: Springer.

Mountford, A., and H. Uhlig. 2002. What are the effects of fiscal policy shocks. CEPR Working Paper no. 3338.

Park, Ha-Seob, and Choi, Jong-Soo. 1997. Some empirical tests on the Ricardian neutrality hypothesis in Korea. The Korean Journal of Public Finance 12 (2).

Park, Jong-Koo. 1995. Government spending and private consumption. The Korean Journal of Public Finance 9.

Park, Ki-baeg, and Park, Hyung-soo. 2002. Fiscal role in economic stabilization. Korea Institute of Public Finance.

Perotti, R. 1999. Fiscal policy in good times and bad. Quarterly Journal of Economics 114:1399-1436.

- 2004. Estimating the effects of fiscal policy in OECD countries. Innocenzo 
Gasparini Institute for Economic Research (IGIER) Working Paper no. 276. Milan, Italy: IGIER.

Ramey, V., and M. Shapiro. 1998. Costly capital reallocation and the effects of government spending. Carnegie-Rochester Conference Series on Public Policy 48:145-94.

Rothenberg, T., and J. Stock. 1997. Inference in a nearly integrated autoregressive model with non-normal innovations. Journal of Econometrics: 269-86.

\section{Comment Wei Li}

The objective of Dr. Hur's paper is to estimate the impact of fiscal policy in Korea. To achieve this goal, Dr. Hur uses quarterly GDP, government revenue, and spending data between 1979:Q1 and 2000:Q4 and estimates structural VAR models. The paper's methodology follows those in Blanchard and Perotti (2002) and Perotti (2004), among others. In one of the SVAR models, it utilizes Korean institutional features - namely, the fiscal principle of expenditure within revenue - to impose identification restrictions. The author finds that estimated fiscal multipliers are in general small using a three variable - GDP, revenue, and spending - SVAR model, but they are larger when a fourth exogenous variable-U.S. GDP or the Real Effective Exchange Rate - is added. One note on presentation: It would be more informative if the impulse responses were transformed to report the Korean won response of each variable to a won shock to one of the fiscal variables - the conventional measure of a fiscal multiplier.

Before discussing the models and the data, let me first review the general economic environment in Korea during the sample period. Between 1979 and 2000, Korea underwent rapid economic transformation. In 1979, the first year in the sample, per capita GDP was \$3,322 in constant 2000 U.S. dollars and agriculture contributed to 21 percent of GDP (World Bank 2006). By 2000, the end year in the sample, per capita GDP more than tripled to $\$ 10,884$, and the contribution of agriculture to GDP fell to only 5 percent. The country's tax system also underwent structural changes. Based on data from the University of Michigan World Tax Database (2006) revenue collected from taxes on international trade and transfers fell from 19 percent of total revenue in 1979 to 7 percent in 1997, while tax revenue as a proportion of GDP increased only marginally from 15 percent to 16 percent. The data also show that the top personal income tax rate was cut from 89.25 percent in 1979 to 40 percent in 1997, during which personal income tax comprised 14.6 percent of total tax revenue in 1979 and 19.0 per-

Wei $\mathrm{Li}$ is an associate professor of business administration at the Darden School of Business, University of Virginia. 